This PDF is a selection from a published volume from the National Bureau of Economic Research

Volume Title: Social Security Programs and Retirement around the World: Micro-Estimation

Volume Author/Editor: Jonathan Gruber and David A. Wise, editors

Volume Publisher: University of Chicago Press

Volume ISBN: 0-226-31018-3

Volume URL: http://www.nber.org/books/grub04-1

Publication Date: January 2004

Title: Income Security Programs and Retirement in Canada Author: Michael Baker, Jonathan Gruber, Kevin Milligan URL: http://www.nber.org/chapters/c10700 


\title{
Income Security Programs and Retirement in Canada
}

\author{
Michael Baker, Jonathan Gruber, and Kevin Milligan
}

\subsection{Introduction}

Government transfers to older persons in Canada are one of the largest and fastest growing components of the government budget. Total expenditures on the three primary transfer programs for older Canadians amounted to $\$ 22.7$ billion in 1998-1999, which represented 20 percent of program spending in the federal budget of that fiscal year. In 1974-1975, total expenditures were only $\$ 3.4$ billion, amounting to just 10 percent of program spending. The contributory public pension faces fiscal similar pressures. In 1975, contributions per capita exceeded benefits per capita by roughly \$200 (1998 dollars). By 1998, benefits per capita instead exceeded contributions per capita by roughly $\$ 200$ (Baker and Benjamin 2000). Moreover, without changes to the system, these trends will likely continue in the foreseeable future. The ratio of persons aged sixty-five and over to persons aged twenty to sixty-four is projected to grow from its current level of 19 percent to over 40 percent by the year 2075. As a result, the payroll

Michael Baker is professor of economics at the University of Toronto, and a faculty research fellow of the National Bureau of Economic Research (NBER). Jonathan Gruber is professor of economics at the MIT, director of the research program on children and research associate of the NBER. Kevin Milligan is assistant professor of economics at the University of British Columbia, and a faculty research fellow of the NBER.

Prepared for the Project on International Social Security Comparisons. We are grateful to Human Resources Development Canada, Statistics Canada and the Social Science and Humanities Research Council (SSHRC; Baker, in particular) for research support; Sue Biscope, Richard Dupuy, Leonard Landry, and Garnett Picot for assistance accessing the data; Terence Yuen for excellent research assistance; and to Paul Finn and participants in seminars at Canadian International Labour Network (CILN), Human Resources Development Canada (HRDC), NBER, and the University of British Columbia for helpful comments. All views expressed in this paper are the authors' own and do not necessarily reflect the views of HRDC or Statistics Canada. 
tax necessary to finance the public pension for older persons, the Canada and Quebec Pension plan, will grow from 7.0 percent in of wages in 2000 to 9.9 percent by the year 2003. Similar cost increases are in store for the transfer programs for older Canadians, which are financed from general revenues: the Old Age Security demogrant, and the income-tested Guaranteed Income Supplement, and the Spouse Allowance programs.

In this context, a notable trend in labor force behavior in Canada is the steady decline in work among many groups of older workers, as documented in figure 2.1. It is particularly striking for older males. Note that the participation rate for forty-five to sixty-four year olds masks a large decline among the older individuals in this group. For example, in 1960, 87 percent of men aged fifty-five to sixty-four were participating in the labor force; by 1999 , this proportion had fallen to 61 percent. For females, any trend towards earlier retirement appears to be swamped by the century-long secular increase in the participation of women.

These time series span a period in which there were a variety of changes in the structure of income support programs for older persons that has made retirement more attractive and work less attractive. In 1960, for example, workers under the age of seventy were not entitled to any income support upon retirement. By the mid-1990s, however, married low-income workers could receive public retirement benefits that actually exceeded their preretirement incomes (Gruber 1999). Of course, it is difficult to causally relate these time trends; there were many other developments over this time period, such as growing private pension coverage and rising incomes, that may have also contributed to the decline in work among older Canadians.

In the United States where there are similar trends, there is an extensive literature that examines the relationship across individuals between social security entitlements and retirement decisions. ${ }^{1}$ This research mostly suggests that social security incentives play an important role in retirement decisions, but a modest one relative to the time trends. In contrast, there is little complementary work in the Canadian context. ${ }^{2}$ Recent studies have examined the impacts of changes in some of these programs in isolation. Baker and Benjamin (1999b) analyze the effects of the removal of the earnings tests from the Canada Pension Plan and Quebec Pension Plan (CPP/ QPP) in the 1970s. They also examine the effect of the introduction of an early retirement option to the QPP in 1984 and to the CPP in 1987 (Baker and Benjamin 1999a, 2001). The determinants of the CPP/QPP take up decision are studied by Tompa (1999). Compton (2001) studies the effect of $\mathrm{CPP} / \mathrm{QPP}$ benefits on retirement, using a short panel of data from the

1. For a review of the literature and some empirical evidence, see Coile and Gruber (2000).

2. Papers by Burbidge (1987) and Pesando and Rea (1977) provide a careful outline of the potential effects of the various Income Security (IS) programs, but no estimate of their empirical magnitude. 


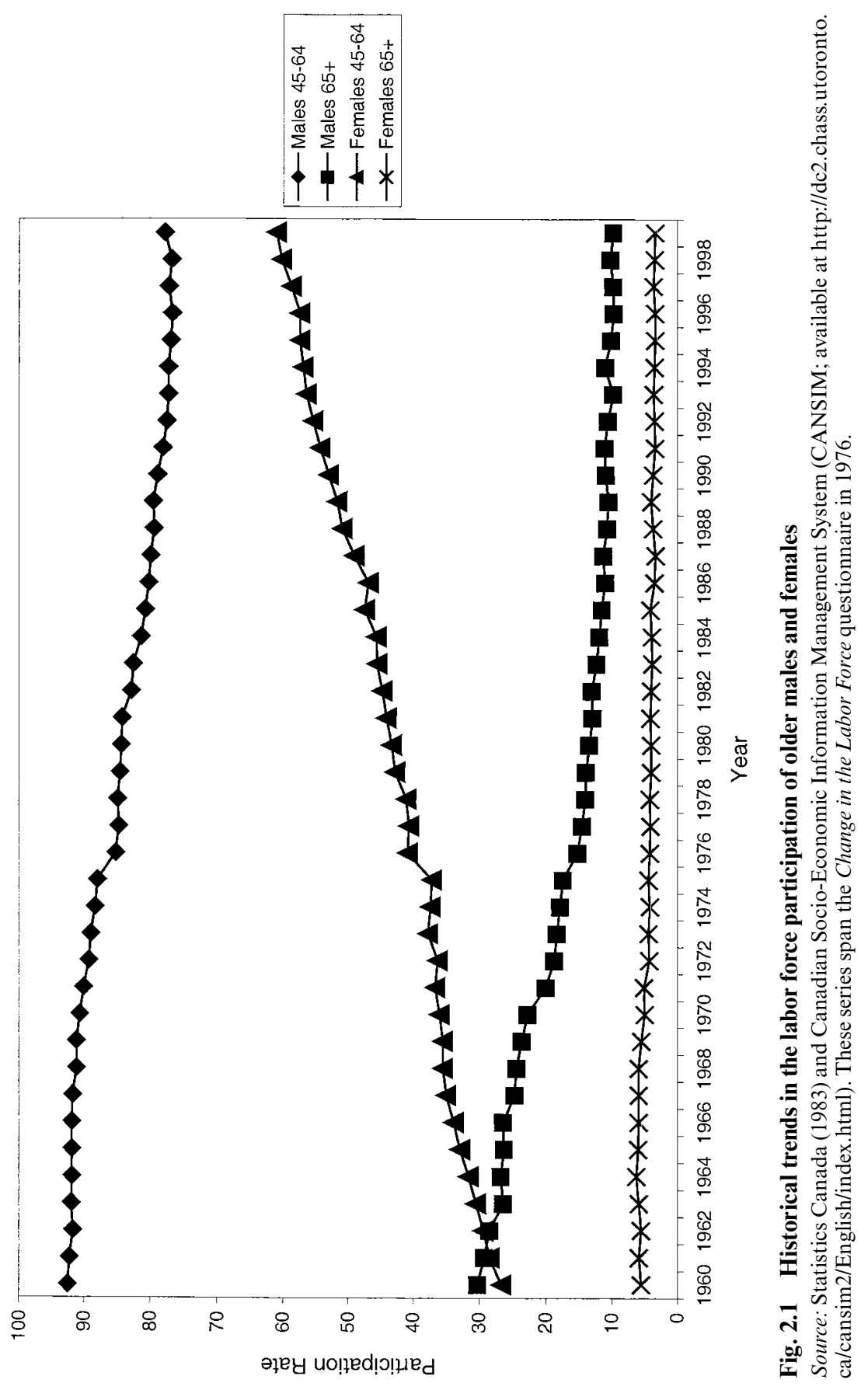


mid-1990s. Finally, Baker (2002) investigates the effects of the introduction of the Spouse Allowance in 1975 on the labor market behavior of eligible couples. A weakness common to all of these papers is that only one component of the IS system is studied in isolation from the others. Our work aims to take a more comprehensive approach by modeling the entire IS system in a unified framework.

In a previous paper (Baker, Gruber, and Milligan 2003), we also addressed the incentive effects of Canada's income security system on retirement. In that paper, we undertook an in-depth examination of the robustness of retirement models to variations in specification and variable definition. Two major findings emerged. First, we found that including rich controls for past and current earnings had a substantial impact on the magnitude of our estimates. Second, our results varied sensibly with changes in specification and variable definition. ${ }^{3}$ We use these findings to guide us in the choice of specification and variable definition we employ for the present paper.

The key to our approach is the building of a comprehensive data set (based on the Statistics Canada Longitudinal Worker File) that has information for a very large sample of older Canadians on their earnings histories, work decisions, marital status and spousal characteristics, and the characteristics of their jobs. These data are employed to construct a simulation model that incorporates the incentives for retirement under the various programs of the Canadian public IS system: the CPP/QPP; the Old Age Security (OAS) system comprising the basic OAS benefit; the Guaranteed Income Supplement (GIS); and the Spouse Allowance (SPA).

For each person in our data set, the financial incentives for retirement are computed along two dimensions. First, the present discounted value of all future entitlements to benefits from the different programs of the public IS system is calculated. This measure of income security wealth (ISW) is recalculated for each year the person appears in our data set to reflect the changes to their benefit entitlements. The second dimension is a measure of how ISW evolves through time. An ISW accrual measure can be calculated by comparing the ISW of the person if they retired in the present year to the ISW of the person if they worked an extra year. Several different measures of accrual are contemplated, which alternatively assume that individuals look only one year forward in making their retirement decision and that individuals look forward to some "optimal" retirement date in making their decision. An empirical model of the retirement decision as a function of these incentive variables, as well as a rich set of control variables designed to capture other impacts on retirement, is then estimated.

There are two findings of importance. First, for the typical worker, the

3. For example, we found that those with workplace pension plans are less sensitive to public pension incentives. 
public IS system provides increasingly strong disincentives to work after age sixty. Workers actually see the present discounted value of there IS entitlement fall from additional work after age sixty-one, and by age sixtynine, the reduction in IS entitlement amounts to 43 percent of what they would earn in that year. Second, there is a significant impact of these disincentives on work decisions. Using both one-year and more forwardlooking measures, we estimate that workers with larger returns to additional work are less likely to leave the labor force.

\subsection{Background}

The decision to retire in Canada is made in the context of a complicated web of program incentives. Below, we first describe in detail the components of the public IS system in Canada. This is followed by a brief description of private pensions and a summary of the different paths to retirement.

\subsubsection{The Old Age Security (OAS) System}

The oldest component of the IS system for older Canadians is the OAS system, which was put into place in 1952, replacing a provincially run income-tested benefits system that had existed since 1927. This program is available to anyone aged sixty-five or over who meets certain residence requirements. ${ }^{4}$ The program originally provided benefits to those of age seventy or over, and the age of eligibility was dropped to sixty-five over a fiveyear period beginning in 1966.

The OAS pension itself is a uniform demogrant that was equal to $\$ 419.92$ in March 2000. Individuals who do not fully meet residence requirements may be entitled to a partial OAS benefit. The OAS benefits have been indexed to the consumer price index (CPI) since 1972, and OAS benefits are fully taxable. In addition, there is a clawback of OAS benefits from very high-income individuals; the OAS for an individual is reduced by 15 cents per dollar of personal net income exceeding $\$ 53,215$. The OAS basic benefit is financed from general taxation revenues.

\subsubsection{The Canada Pension Plan and the Quebec Pension Plan (CPP/QPP)}

The largest component of the income security system is the CPP/QPP. These programs began on 1 January 1966 and are administered separately by Quebec for the QPP and by the federal government for the CPP.

4. Individuals must have been a Canadian citizen or legal resident of Canada at some point before application and must have resided in Canada for at least ten years (if currently in Canada) or twenty years (if currently outside Canada). The benefit is prorated for pensioners with less than forty years of Canadian residence, unless they are "grandfathered" under rules that apply to the persons who were over age twenty-five and had established attachment to Canada prior to July 1977. 
The plan is financed by a payroll tax of 3.5 percent (in 2000) for both employers and employees. This payroll tax is levied on earnings between the year's basic exemption $(\$ 3,500)$ and up to the year's maximum pensionable earnings (YMPE), \$37,600 in 2000 (which approximates average annual earnings). The YMPE is indexed to the growth in average earnings in Canada.

Eligibility for this plan is conditioned on contributions in at least one calendar year during the contributory period. The contributory period begins at age eighteen, or at 1 January 1966 for those who were older than eighteen on that date. It ends at the commencement of the retirement pension or at age seventy, whichever is earlier. Benefits are then computed in several steps.

First, the number of months used to compute the retirement pension is determined by subtracting from the number of months in the contributory period months that the person was (a) receiving a disability pension, (b) rearing small children, ${ }^{5}$ and (c) between age sixty-five and the commencement of the pension, ${ }^{6}$ as well as subtracting 15 percent of the remaining months. The last two of these conditions are subject to the provision that it not reduce the contributory period below 120 months after taking into account the allowable offset for months of disability pension receipt. In addition, excess earnings in one month above one-twelfth of the YMPE may be applied to months in the same year where earnings are below one-twelfth of the YMPE.

Second, the remaining months of earnings history are converted to current dollars, using the following adjustment factor: the ratio of the YMPE in each year (up to 1998) to the average of the YMPE over the three years prior to (and including) the year of pension receipt. This average was raised to four years for benefits claimed in 1998 and five years for benefits beginning in 1999. Finally, the benefit is computed as 25 percent of the average of this real earnings history. This 25 percent ratio has been in place since 1976; from 1967 to 1976, the program was phased in, with the share of average earnings paid out in benefits rising from 2.5 percent in 1967 to 25 percent in 1976. The maximum monthly retirement benefit is $\$ 762.92$ in 2000 .

Until 1984 for the QPP and 1987 for the CPP, benefits could not be claimed before the sixty-fifth birthday, and there was no actuarial adjustment for delayed claiming. Beginning at these times, individuals were allowed to claim benefits as early as age sixty, with an actuarial reduction of 0.5 percent for each month of early claiming (before age sixty-five), and an actuarial increase of 0.5 percent for each month of delayed claiming (after age sixty-five, and up to the age of seventy).

5. This is defined as months in which there was a child less than seven years of age and the worker had zero or below average annual earnings.

6. Periods after age sixty-five to age seventy can be substituted for periods prior to age sixtyfive if this will increase their future retirement pension. 
Since this early retirement provision has been in place, about half the new CPP recipients each year have claimed a retirement benefit before the age of sixty-five. The Office of the Superintendent of Financial Institutions (OSFI) estimated that, after 1991, a CPP pension for someone retiring before the age of sixty-five was, on average, 82 percent of what it would have been had they not opted for early retirement. ${ }^{7}$

Initially, receipt of benefits between ages sixty-five and seventy under the CPP/QPP was conditioned on low earnings levels, with earnings above these ceilings taxed away at high rates. In 1975 and 1977, these earnings tests were eliminated from the CPP and QPP, respectively. With the introduction of early retirement in the 1980s, workers can only claim early benefits if their annual rate of earnings for the year in which the pension is claimed does not exceed the maximum retirement pension payable at age sixty-five. This earnings test is only applied at the point of application, however; after that point, there is no additional check on the individual's earnings. ${ }^{8}$ Moreover, the earnings test does not apply once the individual reaches age sixty-five.

The CPP/QPP benefits are based on an individual's earnings history, and the retirement benefits of one spouse are not linked to that of the other spouse. ${ }^{9}$ There is, however, interdependence through survivor benefits (as well as the interdependencies through the income-tested programs described below). Spouses are eligible for survivor pensions if the deceased contributor made contributions for the lesser of ten years or one-third of the number of years in the contributory period, and if the spouse is over age forty-five or is disabled or has dependent children. For nondisabled spouses with children, the CPP benefit is prorated downward by age between forty-five and thirty-five. ${ }^{10}$ For spouses under age sixty-five, the survivor pension is a combination of a flat-rate portion plus 37.5 percent of the earnings-related pension of the deceased spouse. For spouses age sixtyfive and above, the survivor's pension is equal to 60 percent of the earningsrelated pension. The pension used to calculate the survivor's benefit is not subject to actuarial adjustment. If the surviving spouse is receiving his or her own CPP disability or retirement pension, then the combination of the earnings-related portion of the two pensions cannot exceed the maximum retirement pension available in the year. Under changes made effective in 1998, the two benefits do not stack up to this ceiling; rather the contributor receives the larger of the two earnings-related portions plus 60 percent

7. Special calculations for the 1992 OAS program evaluation performed by OSFI.

8. There are no restrictions on returning to work after the benefit is being paid.

9. Couples do have the option of sharing their benefits for income tax purposes, since taxation is at the individual level. Each spouse can claim up to half of the couple's total CPP/QPP pension credits. The exact calculation depends on the ratio of their cohabitation period to their joint contributory period.

10. The QPP rules for younger surviving spouses differ from those of the CPP. 
of the smaller. Also, if under the age of sixty-five, the survivor receives the flat-rate portion of the survivor benefit or, if a disability pensioner, the (larger) disability flat-rate benefit only.

Children of deceased contributors are also entitled to a CPP survivor's benefit if under age eighteen or a full-time student between eighteen and twenty-five; this benefit is a flat amount. The corresponding QPP benefit ends at age eighteen. There is also a lump-sum death benefit, which is generally equal to one-half of the annual CPP/QPP pension amount up to a maximum $\left(\$ 3,500\right.$ in 1997). ${ }^{11}$

Since 1973, benefits have been legislated to increase annually with the CPI: This annual indexation factor is the ratio of the CPI average over the twelve-month period ending with October of the preceding year to the average of the prior twelve-month period. Benefits are fully taxable by the federal and provincial governments.

Another dimension of the CPP/QPP that is potentially important here is the disability-benefit program. This program provides benefits to those workers unable to work due to disability. The basic benefits structure consists of two portions: a flat-rate portion, which is a lump sum paid to all disabled workers, and an earnings-related portion, which is 75 percent of the applicable CPP/QPP retirement pension calculated with the contributory period ending at the date of disability. This program is fairly stringently screened, and fewer than 5 percent of older Canadian men are on $\mathrm{CPP} / \mathrm{QPP}$ disability.

The maximum CPP disability benefit was increased by 30 percent per month in 1987. Earlier disability coverage was also extended to new entrants. Also, persons receiving survivor benefits no longer had their benefits discontinued on remarriage.

\subsubsection{The GIS and SPA}

The GIS is an income-tested supplement available to recipients of OAS that was introduced in 1967. Individuals must reapply for the GIS each year, and the income test for eligibility is repeated. The definition of income for the purpose of income testing is the same as for income tax purposes, with the important exclusion of OAS pension income. Unlike the OAS clawback or CPP/QPP, GIS benefits are based on family income levels.

There are separate single and married guarantee levels for the GIS; in 2000 (January to March), these were $\$ 499.05$ for singles and $\$ 325.06$ (per person) monthly for the married. Benefits are then reduced at a rate of 50 percent as other income rises, although a couple with one member over age sixty-five and one under age sixty is taxed at only 25 percent with an initial amount of income exempted.

The SPA, which was introduced in 1975 , is an income-tested monthly

11. Under the 1997 legislation, this maximum is fixed at $\$ 2,500$ for all years after 1997 , and in the case of the QPP, all death benefits are set at this level. 
benefit available to sixty to sixty-four-year-old spouses of OAS recipients and to sixty to sixty-four-year-old widows and widowers. For the spouse of an OAS recipient, the benefit is equal to the OAS benefit plus GIS at the married rate; the OAS portion is reduced by 75 percent of other income until it is reduced to zero, and then the combined GIS benefits of both spouses are reduced at 50 percent, as other income rises. For a widowed spouse, the benefit is equal to the OAS plus GIS at the widowed rate, and is "taxedback" equivalently. Both the GIS and SPA guarantees are also indexed to inflation, and neither source of income is taxable by either the federal or provincial governments.

\subsubsection{Other Public Programs}

In addition to the federal retirement programs, there are a variety of provincial programs that provide supplements to low-income retirees. For example, the Guaranteed Annual Income Supplement for the Aged (GAINS-A) program in Ontario provides $\$ 80$ per month to Ontario residents who are recipients of the GIS; these benefits are taxed back at 50 percent as other (non-OAS or GIS) income rises.

\subsubsection{Private Pension Coverage}

Another important feature of the retirement landscape is private pensions. Defined-benefit pension plans share many of the same incentive features as public insurance plans. In fact, many Canadian workers are covered by occupational pensions (known as Registered Pension Plans, or RPPs). In 1997, 41.2 percent of paid workers were covered by occupational pensions, with coverage slightly higher for males than for females (Statistics Canada 1999). Eighty-six percent of plan members were in definedbenefit plans, although the share in defined-contribution plans has been growing recently. Defined-contribution plans may also affect retirement through income effects, but there should not be tax or subsidy effects on the work decision since the payout is not dependent on work patterns.

One weakness of the data that are employed in this study is a lack of information about private pension plan coverage. As a result, it is only possible to include an indicator for whether the individual is likely to have a pension (based on industry of employment), but not for the retirement incentives inherent in that particular pension plan (as is done, for example, in Gruber and Madrian 1995). The methods and data sources for this imputation are described below.

\subsubsection{The Different Paths to Retirement}

Given the differences in the age of initial eligibility across the different IS programs and the availability of other income-support programs before the age of sixty-five, there are a variety of paths that individuals may follow into retirement. Perhaps the most straightforward is from employment onto IS benefits at age sixty-five or later. At these ages an individual is eli- 
gible for all the IS programs so the full potential retirement income from public sources will be available.

Early entitlement for CPP/QPP benefits is available starting at age sixty. Receipt is conditioned on a one-time retirement test, although beneficiaries are free to work once the test is met. Since other sources of support, such as OAS and GIS, are not available until age sixty-five, benefit income may be augmented by earnings from full- or part-time employment. Income is also potentially available from other social insurance programs, such as employment insurance (EI), although there are conditions (e.g., unemployment), and pension income is deducted from any benefits from this source.

Even if early CPP/QPP benefits are not claimed, EI benefits, social assistance benefits, or both are another potential source of support for older workers and thus a path into IS receipt. Also, disabled individuals are eligible for a CPP/QPP pension prior to age sixty that gets automatically converted to a retirement pension at age sixty-five. Finally individuals who participate in RPPs with attractive early retirement packages may start claiming these benefits as a prelude to IS-benefit receipt at later ages.

As explained below, our measure of retirement is based on earnings (or the lack thereof), and therefore employment. We have no direct measure of IS-benefit receipt, so alternative definitions of retirement on this basis are not possible. Our data do record EI-benefit receipt, however, so there is some possibility of tracking individuals who use this path to retirement. Data on other forms of income such as an RPP or social assistance are not available, however, so these paths are also not visible.

In table 2.1, we provide a view of the employment and program participation of older Canadians using data from the 1998 Individual Files of the Survey of Consumer Finances (Statistics Canada 1998a). Full-time work declines dramatically for both males and females between the ages of fifty and sixty-four. Between the ages of sixty and sixty-four, 34 percent of men and just 13 percent of women are in this category. A constant fraction of males work part time in each age group, but for females, the proportion displays a moderate decline before age sixty-five and dramatic fall off in the oldest age group. The proportions not working, and therefore by some measures retired, rise steadily for either sex with age. In the age group sixty to sixty-four, when early CPP/QPP benefit receipt is available, 60 percent of males and 77 percent of females are not working. In the older age group just 10 percent of males and virtually no females are still employed.

The table also reveals that benefits from a variety of programs may support those in the younger age groups that are not working. The proportion drawing a private pension or Registered Retirement Savings plan (RRSP) benefits rises steadily to almost one in three males and one in five females by ages sixty to sixty-four. Income from EI and social assistance flows to a relatively constant proportion (17 percent of males and 13 percent of females) between the ages of fifty and sixty-four. The popularity of the early retirement option of the CPP/QPP program for both sexes is apparent: At 


\begin{tabular}{|c|c|c|c|c|}
\hline & \multicolumn{4}{|c|}{ Age } \\
\hline & $50-54$ & $55-59$ & $60-64$ & $65+$ \\
\hline \multicolumn{5}{|c|}{ Males } \\
\hline \multicolumn{5}{|l|}{ Labor market participation in April 1998} \\
\hline Working full time & 0.76 & 0.60 & 0.34 & 0.07 \\
\hline Working part time & 0.04 & 0.05 & 0.05 & 0.04 \\
\hline Not working & 0.21 & 0.35 & 0.60 & 0.89 \\
\hline \multicolumn{5}{|l|}{ Program participation in 1997} \\
\hline Received OAS/GIS/SPA benefits & 0.00 & 0.00 & 0.03 & 0.97 \\
\hline Received CPP/QPP benefits & 0.05 & 0.07 & 0.44 & 0.92 \\
\hline Received private pension/RRSP benefits & 0.05 & 0.15 & 0.30 & 0.58 \\
\hline Received employment insurance benefits & 0.10 & 0.09 & 0.06 & 0.01 \\
\hline Received social assistance benefits & 0.06 & 0.08 & 0.12 & 0.08 \\
\hline \multicolumn{5}{|c|}{ Females } \\
\hline \multicolumn{5}{|l|}{ Labor market participation in April 1998} \\
\hline Working full time & 0.50 & 0.33 & 0.13 & 0.01 \\
\hline Working part time & 0.14 & 0.13 & 0.10 & 0.02 \\
\hline Not working & 0.36 & 0.54 & 0.77 & 0.97 \\
\hline \multicolumn{5}{|l|}{ Program participation in 1997} \\
\hline Received OAS/GIS/SPA benefits & 0.00 & 0.00 & 0.15 & 0.97 \\
\hline Received CPP/QPP benefits & 0.06 & 0.09 & 0.40 & 0.74 \\
\hline Received private pension/RRSP benefits & 0.03 & 0.10 & 0.20 & 0.35 \\
\hline Received employment insurance benefits & 0.07 & 0.07 & 0.04 & 0.00 \\
\hline Received social assistance benefits & 0.05 & 0.06 & 0.09 & 0.11 \\
\hline
\end{tabular}

Source: Statistics Canada (1998a).

Notes: The statistics on labor market participation are for the reference week of April 1998 used by the survey. The statistics for program participation are for the reference year (1997).

least 40 percent of both males and females between the ages of sixty and sixty-four receive this sort of income. The statistics also show that females are far more likely to take advantage of the SPA program than males and thus receive OAS, GIS, and SPA income between the ages of sixty and sixty-four.

This message here, therefore, is that in the late 1990s a majority of older Canadians are not working by ages sixty to sixty-four. In fact a significant minority are not working by ages fifty-five to fifty-nine. Income support at these younger ages may be coming from private pensions and other social insurance programs. In their early sixties, a significant number of Canadians also avail themselves of the early retirement option in the public pension program.

\subsection{Data}

There are few Canadian data sets that provide both large sample sizes of older individuals and the information necessary to calculate their in- 
centives to retire. This has hindered research on retirement in Canada. To overcome this obstacle, the analysis here makes use of data from a number of sources. These data provide the most comprehensive setting available in which to study the incentives of the Canadian IS system on retirement.

The primary data source is the Longitudinal Worker File (LWF) developed by the Business and Labour Market Analysis (BLMA) Division of Statistics Canada. ${ }^{12}$ It is a 10 percent random sample of Canadian workers for the period 1978-1996. These data are the product of information from three administrative data files: The T-4 file of Revenue Canada, the Record of Employment (ROE) file of Human Resources Development Canada, and the Longitudinal Employment Analysis Program (LEAP) file of BLMA.

The T-4 tax forms are issued annually by employers for any employment earnings that exceed a certain annual threshold; trigger income tax contributions to Canada's public pension plans, or EI premiums; or both. ${ }^{13}$ The earnings information from this source has several advantages over its counterparts in survey data and other administrative files. Most importantly, it is based on employers' reports under the provisions of the income tax laws. Therefore, the earnings variable should be free of the measurement error often observed in survey data.

Employers issue ROE forms to employees in insurable employment ${ }^{14}$ whenever an earnings interruption occurs. Earnings interruptions result from events such as strikes, layoffs, quits, dismissals, retirement, and maternity or parental leave. The reason for the interruption is recorded on the ROE form.

Finally, the LEAP is a longitudinal data file on Canadian businesses at the company level. It is the source of information on the company size and industry of the jobs in which employees work.

The LWF data provide information on the (T-4) wages and salaries and 3-digit industry codes for each job an individual holds in a given year; their age and sex; ${ }^{15}$ the province and size (in terms of employees) of the estab-

12. The construction of the database is described in Picot and Lin (1997) and Statistics Canada (1998b). Our description draws heavily on these sources.

13. The data include incorporated self-employed individuals who pay themselves a salary, but not other self-employed workers. The federal program that provides insurance against unemployment changed names from "unemployment insurance" to "employment insurance" in 1996. Throughout this paper, we use employment insurance (EI) when referring to this program.

14. Over the sample period, insurable employment covers most employer-employee relationships. Exclusion includes self-employed workers, full-time students, and employees who work less than fifteen hours per week and earn less than 20 percent of maximum weekly insurable earnings (20 percent $\bullet \$ 750=\$ 150$ in 1999). Individuals working in insurable employment pay EI contributions on their earnings and are eligible for EI benefits subject to the other parameters of the EI program.

15. Information on the age and sex of individuals is taken from the T-1 tax returns, which individuals file yearly. To obtain this information, therefore, it is necessary that they filed a tax return at least once in the sample period. 
lishment for which they work: $;^{16}$ and their job tenure starting in 1978 . Because T-4s are also issued for EI income, we also observe any insured unemployment, maternity, or sickness spells.

For current purposes, the prime advantage of the LWF data are the earnings histories stretching back to 1978. These were extended further to 1975 for each individual using the T-4 earnings files for these years. For the purposes of calculating CPP/QPP entitlement these histories are still nine years short, however, as these programs started operating in 1966. Our methods of backcasting the missing years are described below.

The focus of the analysis is the period 1985-1995. Separate samples of males and females aged fifty-five through sixty-nine in 1985 are drawn, and then younger cohorts of individuals are added as they turn fifty-five in the years 1986-1991. ${ }^{17}$ Agricultural workers and individuals in other primary industries are excluded. ${ }^{18}$ The sample is selected conditional on working so that the incentives for retirement conditional on being in the labor force are examined. Work is defined as positive T-4 earnings in two consecutive years. If an individual has positive earnings in one year and zero earnings in the next, the year of positive earnings is considered the retirement year. ${ }^{19}$ Given that our data run to 1996 , this means that the last year for which an observation can be formed is 1995, since we need to see one year forward to determine retirement. Since T-4s are not issued to the unincorporated self-employed, this definition of retirement will also capture any persons moving from paid employment into this sector. ${ }^{20}$ Only the

16. The records of the LWF data are at the person, year, and job level. For some calculations it is necessary to aggregate the data to the person and year level. In years in which an individual has more than one job, there will be multiple measures of tenure, industry, firm size, and in some cases province. In these cases, the characteristics of the job with the highest earnings for the year are used.

17. Individuals with missing age, sex, or province variables are excluded from the sample.

18. We make this exclusion because our definitions of retirement are based on earnings, and the earnings streams for these workers, given high rates of self-employment and special provisions in the EI system for fishers and other seasonal workers, are difficult to interpret. For example, individuals in these industries who were too young to collect IS benefits are observed with years of very small earnings (in the hundreds of dollars) and no (or sporadic) evidence of EI benefits. One possibility is that they are primarily unincorporated self-employed, and therefore the majority of their earnings are unobserved.

19. Baker, Gruber, and Milligan (2003) check the robustness of the results under two different definitions of retirement. First, an unemployment insurance (UI)-based definition encompasses UI benefits along with labor market earnings. Second, an earnings-based definition labels someone retired if their earnings fall below a minimum earnings threshold. The results with both of these definitions are broadly consistent with those presented here.

20. While older individuals do work in unincorporated self-employment, the proportion doing so remains fairly constant over our sample period. For males, Canadian census data (Individual Files for 1981, 1986, 1991, and 1996) reveal that the proportion of the population of sixty to sixty-four year olds working in this sector is $0.08-0.09$ ( 0.04 for ages sixty-five and older) in Quebec and 0.13-0.16 (0.06-0.08 for ages sixty-five and older) in the rest of Canada between 1980 and 1995. For females, the statistics are $0.01(0.00-0.01$ for ages sixtyfive and older) in Quebec and $0.20-0.40$ (0.01 for ages sixty-five and older) in the rest of Canada. 
first observed retirement for each individual is considered. If a person reenters the labor market after a year of zero earnings, the later observations are not used. Finally, individuals are only followed until age sixtynine. The retirement of an individual who has positive earnings in every year up to this age is not observed since it presumably occurs after the age of sixty-nine. The working sample, therefore, is a panel data set for the years 1985 through 1995 of individuals between the ages of fifty-five and sixty-nine who worked in 1985 or in the year they turned fifty-five, whichever is later. ${ }^{21}$

The marital status and any spouses of individuals in our sample are identified using information from the T-1 family file maintained by Statistics Canada; T-4 earnings histories for the period 1975-1995 are then constructed for the spouses, again through reference to the T-4 earnings files for these years.

An important piece of information for calculating retirement incentives that is not available in the LWF data is participation in a RPP. We estimate the probability of RPP coverage by 3-digit industry $\operatorname{codes}^{22}$ using crosssectional samples of males or females from the 1986-1990 Labour Market Activity Survey (LMAS) and the 1993-1995 Survey of Labour and Income Dynamics (SLID). In these surveys, individuals are asked if they participate in any RPP. These probabilities are then imputed to individuals in the LWF, matching on industry codes. Probabilities for the years 1991 and 1992 are simple linear interpolations. The sample definitions for these additional data sources are described in the appendix.

\subsection{Earnings and Nonlabor Income Projections}

The following analysis involves constructing each sample individual's entitlement to IS benefits at any given age, as well as estimates of future entitlements. To calculate the CPP/QPP component, we require a full earnings history from 1966, the year in which the program started. As noted above, our earnings information only extends back until 1975. In estimating future entitlements, we must project future earnings to construct the relevant earnings history. Therefore, both earnings backcasts and forecasts are needed for these calculations.

After experimenting with a number of projection methods, earnings are

21. The ROEs were considered as an alternative source of information on when individuals retired. It was found, however, that generally less than one-third of individuals who retired in the earnings sense (e.g., had zero T-4 earnings), also had "retirement" coded on their last ROE. "Still working" or "unknown" were the most common codes for those in the complementary group. The ROEs, therefore, would appear to impose a restrictive definition of retirement that has an unknown basis.

22. Some industries are aggregated to obtain sufficient sample sizes. Unfortunately, the sample sizes of these data sets would not permit us to calculate these probabilities exclusively for older individuals. 
forecasted by applying a real growth rate of zero percent per year to the average of an individual's observed earnings in the three years preceding the retirement year. Within-sample evaluation revealed that this method is a better predictor (in a mean-squared error sense) of future earnings than methods involving a projection equation that included demographic variables, lagged earnings, and individual fixed effects.

To backcast the missing earnings data, cohort-specific earnings growth rates calculated from the 1972, 1974, and 1976 Census Family files of the Survey of Consumer Finance (SCF; Statistics Canada, various years) ${ }^{23}$ were applied to a three-year average of an individual's last valid earnings observations in the LWF sample. This allows us to construct earnings histories back to 1971. For the remaining five years, earnings growth rates implied by the cross-sectional profile from the 1972 SCF were used, appropriately discounted for inflation and productivity gains using the industrial composite wage for the period 1966-1970. ${ }^{24}$

The GIS and SPA and OAS components of IS benefits are fully or partly means tested. Our data set contains no information on nonlabor income, although these are clearly a crucial input to calculating entitlement to these benefits. To project nonlabor income, we construct age profiles of familylevel income by sex, region, and industry and sex, region, and maritalstatus cells for individuals in and out of the labor market, respectively. ${ }^{25}$ The data for these profiles are from the 1986 and 1991 Census Family files of the Canadian Census (Statistics Canada, various years). The measure of nonlabor income that we use includes both investment income and income from private pensions. Details on the formal definition of the measure are provided in the appendix.

When entitlement is projected in future retirement years, it is necessary to impute the level of nonlabor income an individual will receive at different ages when they are retired. To do this, we use the age profile for this income for individuals out of the labor market in the relevant sex, region, and marital-status cell. Likewise, for individuals who continue to work past age sixty-five (sixty for the SPA), it is necessary to impute their level of nonlabor income to calculate the benefits they might draw from OAS, GIS, or SPA. To do this, the age profile for employed individuals in the relevant sex, region, and industry cell is used. The sample and cell definitions that are employed are also described in the appendix.

Both projected earnings and nonlabor income are net of federal and provincial income taxes. Also deducted are the employee's portions of the $\mathrm{CPP} / \mathrm{QPP}$ payroll tax that they would pay if they worked. In either case, the

23. We use samples of paid workers with positive earnings in the relevant birth cohorts.

24. The data on the industrial composite wage are from Statistics Canada (1983). The obvious limitation of this backcasting approach is that we will not predict absences from the labor market, which may be important at younger ages.

25 . The age profiles are appropriately inflated by the CPI for use in future years. 
parameters of the tax system are held constant in real terms for all future years.

\subsection{Construction of the Incentive Measures}

\subsubsection{Benefit Entitlements}

The retirement incentives inherent in the various programs of the Canadian IS system for seniors are calculated regarding the OAS, the GIS and SPA, and the CPP/QPP. The first step is to calculate an individual's entitlement in any given year. This will involve both their own entitlements to each of the programs as well as the entitlements of any spouse.

The OAS benefit is the most straightforward as it is a uniform benefit available to anyone who is sixty-five years or older. Two possible complications are the residency requirements and the clawback of benefits from high-income recipients. The residency requirement for this benefit is not implemented, as there is no information on the place of birth or year of arrival in Canada of individuals in the sample. The clawback provisions (starting in 1989) are fully implemented, however, based on projections of labor and nonlabor income.

Either the GIS entitlement, SPA entitlement, or both are functions of the age requirements, described previously, and family income. The ages of individuals and any spouses are directly observable in the data. The income test on benefits is again fully incorporated based on projections of labor and nonlabor income.

As discussed above, nonlabor income is projected using census data and matched to our data. For each individual, the OAS and GIS and SPA benefit entitlement with and without the imputed level of nonlabor income is calculated. The two results are then averaged using as weights the cellspecific probability that nonlabor income is positive.

The calculation of CPP/QPP entitlement involves constructing an individual's and their spouse's earnings history over the contributory period. Given the age range in the sample, this is the period starting in 1966. The direct observations on T-4 earnings back to 1975 and predicted earnings in the period 1966-1974 are used. The dropout provisions for years between the sixty-fifth birthday and the commencement of retirement and for lowearnings months up to 15 percent of the contributory period are fully implemented. Disabilities or time spent in care of children are not observed, however, and therefore deletions for these reasons are not captured. ${ }^{26}$ This information in tandem with earnings projections for future years permits

26. Note that the dropout provisions for childcare came in to effect in 1977 under the QPP and 1978 under the CPP. The childbearing years of many females in our sample will have been prior to these dates. 
the construction of average pensionable earnings (APE) at all future retirement dates for any given individual. The reforms of the CPP/QPP system over the period are also accounted for, including the introduction of early retirement to the CPP, the retirement test on benefit receipt at ages sixty to sixty-four, and the actuarial adjustment to benefits for initiating benefit receipt at ages other than sixty-five, all in 1987.

\subsubsection{Spousal Behavior}

A complete model of family labor supply is beyond the scope of this paper. The simplifying assumption that the spouse starts collecting any entitlement at the earliest age possible under the current rules of IS programs is made: For most of the sample period, this is age sixty-five for OAS and GIS, age sixty for the SPA, and age sixty for the CPP/QPP. For CPP/QPP benefits prior to age sixty-five and any income-tested benefit, the assumption implies a cessation of the spouse's employment (i.e., retirement). Gruber (1999) and Baker and Benjamin (2000) provide estimates of age and employment profiles as well as employment hazards (the conditional probability of labor market exit) for older men and women over the sample period. This evidence provides some justification for this assumption about labor market exit rates in our analysis of the male sample in which spouses are females. On the other hand, this assumption may prematurely remove the male spouses of individuals in our sample of females from the labor market. This is unlikely to have a large effect on our estimates, as the independence across spouses in determination of most of the benefits means that spousal retirement is only a minor contributor to IS incentive calculations.

\subsubsection{The Present Discounted Value of Income Security Wealth (ISW)}

Once these calculations of entitlement for each of the programs are made, the expected net present value of the family's ISW associated with each retirement date is constructed. For single workers, this is the sum of future benefits discounted by time preference and survival probabilities. For married workers, we account for the likelihood of the joint survival of worker and the spouse, and the survivor provisions of the CPP/QPP and SPA, as described in more detail in Gruber (1999). We use a real discount rate of 3 percent and survival probabilities from the age- and sexspecific Canadian life tables from Statistics Canada (Statistics Canada 1984).

\subsubsection{The One-Year Accrual Calculation}

We compute a number of different incentive variables using these estimates of the present discounted value (PDV) of ISW at all future retirement dates. The first is the one-year accrual of ISW resulting from an ad- 
ditional year of work. In the Canadian system, an additional year of work can raise ISW through the dropout provisions of the CPP/QPP, and it can either raise or lower ISW through the actuarial adjustment of benefits. ${ }^{27}$

The first of these factors is fairly small. In the Canadian system, the contributory period is a fixed age interval, so that other things equal, the marginal year replaces only 15 percent of a low-earnings year. ${ }^{28}$ Furthermore, this benefit is attenuated in the period examined here, by the real decline in the YMPE in the early 1970s. Initially set to match average wages, the YMPE declined dramatically in the initial years of the program, falling to 67 percent of the industrial composite wage in $1973 .{ }^{29}$ In 1975, both the CPP and QPP were amended to allow the YMPE to rise at a rate of 12.5 percent per annum until equality with average wages was reattained, but this did not occur until 1987. The upshot is that even individuals with low wages would have made the maximum contribution to the system in the 1970s. Therefore, a marginal year in the late 1980s and early 1990s would not necessarily dominate earlier years when the relative YMPE was much lower.

Starting at age sixty (in years 1987 and forward for the CPP), an additional year of work also implies a delay in claiming and, thus, both an (upward) actuarial adjustment in benefits and reduction in the years of potential receipt. The actuarial adjustment between ages sixty and seventy is a linear 6 percent per annum. Whether this provides a net increment or decrement to ISW depends on the size of the adjustment relative to the expected number of years of remaining lifetime over which benefits will be collected. Given the linear nature of the adjustment, it will clearly become more and more unfair with age. This adjustment also interacts with the income testing of the GIS and SPA program. Low-income individuals may get some of the actuarial reduction in CPP/QPP benefits for early retirement back starting at age sixty-five through qualification for a higher GIS benefit. This further increases the disincentives for additional work after age sixty for those who are likely to be on the GIS program. Another way of looking at this is that the actuarial increase in benefits for delaying retirement may reduce entitlement to means-tested benefits starting at age sixty-five. For these individuals, therefore, the effective actuarial adjustment is less than 6 percent per year and therefore, much more likely to be unfair.

27. Here we use the value of the accrual, rather than normalizing the accrual by earnings to form an implicit tax or subsidy, as is done in Gruber (1999). We do this because we are controlling for earnings itself in the regression model, so that we, in essence, capture both pieces of the incentive to work (earnings and ISW accrual) separately.

28. This contrasts, for example, with the U.S. Social Security system where the substitution is one for one: For those with less than thirty-five years of work, the marginal year replaces a zero in the social security (SS) calculation; for those with thirty-five years or more of work, it replaces a full low-earnings year.

29. The YMPE equaled 99.8 percent of the industrial composite wage in 1966. 


\subsubsection{The Peak Value Calculation}

Forward-looking measures of retirement incentives that involve the future path of ISW are also considered. The simple measure of one-year accrual only accounts for the immediate benefit to working an additional year. But an additional year of work also sustains the option of retiring at an even later date. The value of this choice can be important if there are large nonlinearities in the accrual profile. For example, if there is a small negative accrual at age fifty-nine, but a large positive accrual at age sixty, it would be misleading to say that the system induces retirement at age fiftynine; the disincentive to work at that age is dominated by incentives to work at age sixty.

One way of capturing this possibility is to use the peak value calculation suggested by Coile and Gruber (2000). Rather than taking the difference between ISW today and next year, peak value takes the difference between ISW today and in the year in which the expected value of ISW is maximized. This measure therefore captures the trade-off between retiring today and working until a year with a much higher ISW: the option dollar value of continued work. In years beyond the year of peak expected value ISW, this calculation collapses to the simple one-year accrual variable.

\subsubsection{The Option Value Calculation}

If a utility function that captures work preferences can be appropriately defined, then an approach that compares the utility of retirement at future dates is preferable. To explore this approach, the option value calculation of Stock and Wise (1990) is used. Here the utility of retiring today is compared to its value at the optimal retirement year in the future. The calculation uses a specification of the individual's indirect utility function:

$$
V_{t}(R)=\sum_{s=t}^{R-1} p_{s \mid t} d^{s-t}\left(y_{s}\right)^{g}+\sum_{s=t}^{T} p_{s \mid t} d^{s-t}\left[k \cdot B_{s}(R)\right]^{g},
$$

where

$R$ is the retirement date,

$d$ is the discount rate,

$p$ is the probability of being alive at some future date conditional on being

alive today,

$y$ is income while working,

$B$ is retirement benefits,

$g$ is the parameter of risk aversion,

$k$ is a parameter to account for disutility of labor $(k \geq 1)$

$T$ is maximum life length.

In this model, additional years of work have three effects. First, they raise total wage earnings, increasing utility. Second, they reduce the number of 
years over which benefits are received, lowering utility. Third, they may raise or lower the benefit amount depending on the shape of the benefit function $B(R)$. The last two effects receive greater weight than the first due to the disutility of labor. The optimal year for retirement is the year in which the utility gained from additional earnings is outweighed by the utility lost from the reduction in retirement income. The option value is the difference in utility from retirement at the optimal date and retirement today.

Relative to peak value, option value has one major advantage and several disadvantages. The advantage is that the reference year in the peak value calculation (the year in which ISW is maximized) is arbitrary; there is no particular reason why this should be the year to which a given worker compares this year's ISW in making their retirement decision. The option value approach more carefully specifies the optimal retirement date, and as such provides an economic basis for the reference year.

Offsetting this advantage, however, are a number of disadvantages. The option value approach requires a particular specification of the indirectutility function and evaluation of its structural parameters. Also, earnings enter directly into the utility calculation and thus will drive some part of the variation of the option value across individuals. If earnings are in turn correlated with some unobserved component of tastes for retirement, the identification of the option value effects can be undermined.

To implement this approach, values of $k$ (the parameter for the disutility of labor), $d$ (the discount rate), and $g$ (the parameter of risk aversion) are taken from the literature. Following Stock and Wise (1990), $k=1.5$ and $g$ $=0.75$, while $d=0.03$, following Coile and Gruber (2000). Sensitivity analysis suggests that the results are not dramatically different for sensible variations in these parameter values.

\subsubsection{Sample Estimates of the Different Incentive Measures}

In table 2.2, we provide information on the distribution of the one-year accrual measure, by age, for the male sample. The median ISW rises to a peak at age sixty-one, then starts on a smooth descent. The median oneyear accrual is positive to age sixty, but becomes increasingly negative thereafter. The initial positive accrual is due to the dropout provisions, which work in favor of the worker with the median PDV of ISW. This effect is attenuated with age, however, as the implied larger CPP/QPP entitlement reduces GIS and SPA entitlement through the income test. The negative accruals start at age sixty-one as the early retirement provisions of the $\mathrm{CPP} / \mathrm{QPP}$ come into play. Important here is that the linear CPP/QPP actuarial adjustment becomes increasingly unfair as the person delays retirement. There is an additional consideration for individuals who will eventually claim on GIS benefits (45 percent of OAS pensioners received GIS benefits in 1990). The higher CPP/QPP benefits gained by delaying retire- 
The Distribution of the One-Year Accrual, by Age (male sample)

\begin{tabular}{|c|c|c|c|c|c|c|c|c|}
\hline Age & $N$ & $\begin{array}{l}\text { Median } \\
\text { ISW } \\
\text { (\$) }\end{array}$ & $\begin{array}{l}\text { Median } \\
\text { (\$) }\end{array}$ & $\begin{array}{c}\text { 10th } \\
\text { Percentile } \\
\text { (\$) }\end{array}$ & $\begin{array}{c}90 \text { th } \\
\text { Percentile } \\
\text { (\$) }\end{array}$ & SD & $\begin{array}{l}\text { Median } \\
\text { Tax } \\
\text { Rate 1 }\end{array}$ & $\begin{array}{l}\text { Median } \\
\text { Tax } \\
\text { Rate 2 }\end{array}$ \\
\hline 55 & 57,387 & 107,533 & 1,169 & 547 & 1,736 & 467 & -0.049 & -0.042 \\
\hline 56 & 61,167 & 108,702 & 829 & 0 & 1,775 & 655 & -0.038 & 0.005 \\
\hline 57 & 63,818 & 109,531 & 534 & 0 & 1,821 & 729 & -0.027 & 0.036 \\
\hline 58 & 65,091 & 110,065 & 320 & 0 & 1,873 & 775 & -0.018 & 0.037 \\
\hline 59 & 65,541 & 110,385 & 218 & 0 & 1,933 & 807 & -0.012 & 0.038 \\
\hline 60 & 60,051 & 110,603 & 30 & $-1,259$ & 1,620 & 1,103 & -0.002 & 0.077 \\
\hline 61 & 52,539 & 110,633 & -249 & $-1,491$ & 1,270 & 1,068 & 0.014 & 0.085 \\
\hline 62 & 45,898 & 110,384 & -648 & $-1,987$ & 853 & 1,108 & 0.037 & 0.085 \\
\hline 63 & 39,711 & 109,737 & $-1,053$ & $-2,479$ & 505 & 1,217 & 0.063 & 0.096 \\
\hline 64 & 33,776 & 108,684 & $-1,397$ & $-2,903$ & 209 & 1,335 & 0.086 & 0.186 \\
\hline 65 & 27,118 & 107,287 & $-2,931$ & $-4,694$ & -838 & 1,518 & 0.188 & 0.367 \\
\hline 66 & 13,932 & 104,356 & $-3,334$ & $-5,095$ & $-1,252$ & 1,514 & 0.237 & 0.413 \\
\hline 67 & 9,008 & 101,022 & $-3,718$ & $-5,403$ & $-1,532$ & 1,497 & 0.298 & 0.396 \\
\hline 68 & 6,812 & 97,304 & $-4,040$ & $-5,749$ & $-1,826$ & 1,513 & 0.366 & 0.327 \\
\hline 69 & 5,480 & 93,265 & $-4,340$ & $-6,026$ & $-2,131$ & 1,523 & 0.425 & 0.340 \\
\hline
\end{tabular}

Source: The numbers reported are the result of the ISW calculation described in the text. Median tax rate 1 is calculated from the analysis sample. Median tax rate 2 is from Gruber (1999).

Notes: $N=$ number of observations; ISW = Income Security Wealth; SD = standard deviation. All dollar values in 1998 U.S. dollars. Definitions of the different measures of ISW accrual are provided in the text.

ment, either through improving the earnings history or the actuarial adjustment, are offset by reduced income-tested GIS benefits at older ages. That is, the means-tested aspects of the income security system essentially "tax back" the actuarial adjustment, reducing the incentive to work past age sixty. The net effect of these factors is increasingly negative, as the median accrual falls from $-\$ 249$ to $-\$ 1,397$ between ages sixty-one and sixtyfour.

The median accrual rises in absolute value at age sixty-five as OAS and GIS benefits come on line (there are SPA benefits in this range as well, given that the spouses of these male workers are typically several years younger). This jump reflects the fact that additional earnings after sixty-five will decrease the OAS, GIS, and SPA benefits through the income test for many workers. From age sixty-six to age sixty-nine, the accrual becomes more negative quickly, reflecting the increasingly unfair actuarial adjustment of $\mathrm{CPP} / \mathrm{QPP}$ benefits and the fact that continued work sacrifices GIS benefits, through the income test, and OAS benefits, if earnings are high enough, through the income tax clawback. Overall, the loss in ISW wealth in table 2.2 is substantial between ages sixty-one and sixty-nine: The sum of the median accrual over these ages is $-\$ 21,709$.

In the next to last column the median tax or subsidy rates are reported. This is calculated as the median ratio of the one-year accrual to current af- 
The Distribution of the Peak Value and Option Value Accrual, by Age (male sample)

\begin{tabular}{|c|c|c|c|c|c|c|c|c|}
\hline \multirow[b]{2}{*}{ Age } & \multicolumn{4}{|c|}{ Peak Value } & \multicolumn{4}{|c|}{ Option Value } \\
\hline & $\begin{array}{l}\text { Median } \\
(\$)\end{array}$ & $\begin{array}{c}10 \text { th } \\
\text { Percentile } \\
(\$)\end{array}$ & $\begin{array}{c}90 \text { th } \\
\text { Percentile } \\
(\$)\end{array}$ & SD & $\begin{array}{l}\text { Median } \\
(\$)\end{array}$ & $\begin{array}{c}10 \text { th } \\
\text { Percentile } \\
(\$)\end{array}$ & $\begin{array}{c}90 \text { th } \\
\text { Percentile } \\
(\$)\end{array}$ & SD \\
\hline 55 & 2,997 & 1,012 & 9,363 & 3,423 & 16,804 & 7,814 & 26,397 & 10,764 \\
\hline 56 & 1,998 & 120 & 8,283 & 3,399 & 14,839 & 7,040 & 23,719 & 9,983 \\
\hline 57 & 1,164 & 0 & 7,061 & 3,082 & 12,965 & 5,980 & 21,106 & 9,484 \\
\hline 58 & 807 & 0 & 5,592 & 2,642 & 11,131 & 4,686 & 18,657 & 8,771 \\
\hline 59 & 577 & 0 & 4,188 & 2,183 & 9,396 & 3,555 & 16,296 & 8,011 \\
\hline 60 & 47 & $-1,258$ & 2,929 & 2,100 & 8,151 & 2,755 & 14,319 & 6,903 \\
\hline 61 & -247 & $-1,491$ & 1,766 & 1,798 & 6,993 & 2,108 & 12,324 & 6,790 \\
\hline 62 & -647 & $-1,987$ & 1,149 & 1,621 & 5,878 & 1,424 & 10,471 & 6,333 \\
\hline 63 & $-1,053$ & $-2,479$ & 654 & 1,503 & 4,820 & 835 & 8,707 & 5,841 \\
\hline 64 & $-1,397$ & $-2,902$ & 278 & 1,374 & 3,808 & 381 & 6,996 & 5,141 \\
\hline 65 & $-2,931$ & $-4,694$ & -838 & 1,563 & 2,698 & 97 & 5,556 & 4,675 \\
\hline 66 & $-3,334$ & $-5,095$ & $-1,252$ & 1,549 & 1,695 & $-2,186$ & 4,538 & 5,142 \\
\hline 67 & $-3,718$ & $-5,403$ & $-1,532$ & 1,520 & 977 & $-4,177$ & 3,400 & 4,886 \\
\hline 68 & $-4,040$ & $-5,749$ & $-1,826$ & 1,529 & 516 & $-4,865$ & 2,270 & 4,427 \\
\hline 69 & $-4,340$ & $-6,026$ & $-2,131$ & 1,523 & 210 & $-5,257$ & 1,138 & 3,151 \\
\hline
\end{tabular}

Source: The numbers reported are the result of the ISW calculation described in the text.

Notes: $N=$ number of observations; $\mathrm{SD}=$ standard deviation. All dollar values in 1998 U.S. dollars. Definitions of the different measures of ISW accrual are provided in the text.

ter tax earnings. After the initial period of subsidy, the tax rate becomes positive at age sixty-one. By age sixty-nine, the median tax rate is about 43 percent. These figures are somewhat lower than the estimates from Gruber (1999), presumably reflecting the fact that the dropout provisions have greater value here because we use real rather than simulated earnings histories. That is, if the real earnings history is more variable than a simulated earnings history, there will be more value to replacing lower-earnings years that will in turn increase the incentive to continue working.

The median accrual masks considerable variation in the one-year accrual across individuals. For example, the standard deviation averages $\$ 1,122$ across age groups. The accrual at the ninetieth percentile does not turn negative until age sixty-five. Presumably few of these individuals would qualify for GIS due to private pensions and savings. Many should also be in the clawback range for the OAS. As a consequence, we might not expect age sixty-five to be so pivotal for these individuals. That said, average nonlabor income is imputed to individuals, and this will be more inappropriate for people in the tails of the income distribution.

Corresponding information for the peak value accrual is provided in table 2.3. Not surprisingly, the main difference from the one-year accrual is at ages fifty-five to fifty-nine. The median accrual is larger at these ages, but the change is fairly modest. For example, the median one-year accrual at 
The Distribution of the One-Year Accrual, by Age (female sample)

\begin{tabular}{|c|c|c|c|c|c|c|c|}
\hline Age & $N$ & $\begin{array}{l}\text { Median } \\
\text { ISW } \\
\text { (\$) }\end{array}$ & $\begin{array}{l}\text { Median } \\
(\$)\end{array}$ & $\begin{array}{c}10 \text { th } \\
\text { Percentile } \\
(\$)\end{array}$ & $\begin{array}{c}90 \text { th } \\
\text { Percentile } \\
\text { (\$) }\end{array}$ & $\mathrm{SD}$ & $\begin{array}{c}\text { Median } \\
\text { Tax } \\
\text { Rate } 1\end{array}$ \\
\hline 55 & 43,062 & 102,235 & 673 & 116 & 1,426 & 475 & -0.049 \\
\hline 56 & 43,889 & 102,908 & 563 & 79 & 1,408 & 492 & -0.045 \\
\hline 57 & 44,160 & 103,471 & 526 & 20 & 1,445 & 531 & -0.045 \\
\hline 58 & 43,528 & 103,997 & 484 & 0 & 1,483 & 568 & -0.045 \\
\hline 59 & 42,611 & 104,481 & 448 & 0 & 1,510 & 597 & -0.046 \\
\hline 60 & 37,306 & 104,929 & 107 & -980 & 1,455 & 933 & -0.011 \\
\hline 61 & 31,320 & 105,036 & -30 & $-1,130$ & 1,115 & 895 & 0.003 \\
\hline 62 & 26,480 & 105,007 & -307 & $-1,460$ & 777 & 915 & 0.030 \\
\hline 63 & 22,364 & 104,700 & -614 & $-1,815$ & 560 & 996 & 0.061 \\
\hline 64 & 18,646 & 104,086 & -831 & $-2,198$ & 403 & 1,090 & 0.087 \\
\hline 65 & 15,072 & 103,255 & $-2,391$ & $-3,962$ & -642 & 1,278 & 0.241 \\
\hline 66 & 8,298 & 100,865 & $-2,631$ & $-4,364$ & -797 & 1,365 & 0.301 \\
\hline 67 & 5,564 & 98,234 & $-2,825$ & $-4,748$ & -899 & 1,467 & 0.357 \\
\hline 68 & 4,196 & 95,409 & $-3,038$ & $-5,130$ & $-1,157$ & 1,533 & 0.423 \\
\hline 69 & 3,312 & 92,371 & $-3,321$ & $-5,389$ & $-1,406$ & 1,585 & 0.481 \\
\hline
\end{tabular}

Source: The numbers reported are the result of the ISW calculation described in the text. Median tax rate 1 is calculated from the analysis sample.

Notes: See table 2.2 .

age fifty-seven is $\$ 534$, while the median peak value accrual is $\$ 1,164$. Correspondingly, adding together the median one-year accruals in table 2.3 between ages fifty-five and sixty, the distance to the peak is not that large. The primary inducement to continued work at older ages is the dropout provisions of the CPP/QPP, which, as previously explained, are modest and attenuated in the period that we examine due to the real decline in YMPE over the 1970s. That is, continued work may not qualify the individual for a larger CPP/QPP entitlement. Furthermore, the CPP/QPP is only one of three components of ISW. Therefore, we might expect the financial option value of continued work to be modest at older ages. ${ }^{30}$ Note that once age sixty is reached, the peak value calculation is the same as the oneyear calculation for most individuals, since they have already reached their peak.

Table 2.3 also contains information on the option value accrual. Here the accrual is positive throughout the age range, reflecting the fact that the median optimal age of retirement by this measure is at age seventy or seventy-one. The magnitudes of these numbers are difficult to interpret as they are in units of utility.

In table 2.4 we present corresponding information on the one-year ac-

30. In contrast, Coile and Gruber (2000) report large differences between one-year and peak value accrual for the United States. This is not surprising because, as previously explained, the dropout provisions of the U.S. Social Security system can lead to large changes in SS wealth with work at older ages. 
crual in the female sample. The age profile of the one-year accrual largely reflects the same factors as the profile for males (e.g., dropout provisions of the CPP/QPP and the straight-line actuarial adjustment of CPP/QPP benefits). One might reason that females' lower earnings entitle them to smaller CPP/QPP benefits, and therefore their ISW entitlement should be smaller. This effect is attenuated by the large relative decline in the YMPE over the 1970s and the fact that CPP/QPP is only one of three components of the IS package. Another consideration is that the longer lifespan of females means that the actuarial adjustment for delayed receipt of CPP/QPP benefits will be fairer for this group. We can see this in the smaller proportionate changes in the accrual over the age profile. For males, the median accrual increases (in absolute value) by $\$ 1,427$ between ages sixty and sixty-four and by $\$ 1,409$ between ages sixty-five and sixty-nine. For females, the corresponding changes are $\$ 938$ and $\$ 931$ respectively. Also it is important to remember that the sample individuals are selected by conditioning on positive earnings in the first year the individual enters the sample. These, therefore, are a select sample of females who worked at older ages, yet belong to birth cohorts that historically have not had high participation rates. ${ }^{31}$

The peak value and option statistics presented in table 2.5 are also very similar to their counterparts for males. Again the early peak in ISW and the lack of any strong variation in accrual mean there are only modest differences between the one-year and peak value calculations.

In figures 2.2 and 2.3 we graph the age profiles of the median of the various measures of accrual. The relative levels are meaningless, as the option value is measured in utility units. A comparison of the age profiles of the different measures of accrual, however, is meaningful, highlighting the differences among the measures. For both sexes the one-year and peak value have very similar age profiles. The median accruals decline over the full age range, with increases in the rate of decline noticeable at ages sixty and sixty-five. The difference in the peak value measure is entirely in the age range fifty-five to fifty-nine. The option value calculation provides a very different profile, as accrual declines continuously at a decreasing rate over the age range.

\subsection{Empirical Framework and Estimation Results}

\subsubsection{The Empirical Framework}

The regression equation relates the retirement decisions of individuals to their demographic and economic characteristics as well as their ISW.

31. The participation rate of forty-five- to sixty-four-year-old females was 41 percent in 1976, 48 percent in 1986, and 58 percent in 1996 (the source is CANSIM, available at http:// dc2.chass.utoronto.ca/cansim2/English/index.html). 
The Distribution of the Peak Value and Option Value Accrual, by Age (female sample)

\begin{tabular}{|c|c|c|c|c|c|c|c|c|}
\hline \multirow[b]{2}{*}{ Age } & \multicolumn{4}{|c|}{ Peak Value } & \multicolumn{4}{|c|}{ Option Value } \\
\hline & $\begin{array}{l}\text { Median } \\
\text { (\$) }\end{array}$ & $\begin{array}{c}\text { 10th } \\
\text { Percentile } \\
(\$)\end{array}$ & $\begin{array}{c}90 \text { th } \\
\text { Percentile } \\
(\$)\end{array}$ & SD & $\begin{array}{l}\text { Median } \\
\text { (\$) }\end{array}$ & $\begin{array}{c}\text { 10th } \\
\text { Percentile } \\
(\$)\end{array}$ & $\begin{array}{c}90 \text { th } \\
\text { Percentile } \\
(\$)\end{array}$ & SD \\
\hline 55 & 2,684 & 708 & 7,407 & 2,683 & 10,589 & 2,994 & 19,840 & 7,051 \\
\hline 56 & 2,205 & 399 & 6,639 & 2,576 & 9,431 & 3,153 & 17,416 & 6,254 \\
\hline 57 & 1,736 & 182 & 5,771 & 2,345 & 8,253 & 2,859 & 15,323 & 5,484 \\
\hline 58 & 1,235 & 44 & 4,671 & 2,041 & 7,135 & 2,377 & 13,323 & 4,786 \\
\hline 59 & 741 & 0 & 3,562 & 1,785 & 6,038 & 1,836 & 11,498 & 4,257 \\
\hline 60 & 194 & -979 & 2,769 & 1,821 & 5,230 & 1,421 & 10,193 & 3,859 \\
\hline 61 & -14 & $-1,130$ & 2,019 & 1,586 & 4,531 & 1,149 & 8,910 & 3,613 \\
\hline 62 & -303 & $-1,460$ & 1,382 & 1,399 & 3,795 & 828 & 7,624 & 3,262 \\
\hline 63 & -612 & $-1,815$ & 944 & 1,284 & 3,118 & 517 & 6,322 & 2,787 \\
\hline 64 & -831 & $-2,198$ & 506 & 1,164 & 2,427 & 242 & 5,203 & 2,543 \\
\hline 65 & $-2,391$ & $-3,962$ & -642 & 1,363 & 1,626 & $-1,691$ & 3,991 & 2,491 \\
\hline 66 & $-2,631$ & $-4,364$ & -795 & 1,451 & 960 & $-2,309$ & 3,057 & 2,248 \\
\hline 67 & $-2,825$ & $-4,748$ & -899 & 1,519 & 576 & $-3,560$ & 2,245 & 2,351 \\
\hline 68 & $-3,038$ & $-5,130$ & $-1,157$ & 1,557 & 283 & $-4,343$ & 1,521 & 2,404 \\
\hline 69 & $-3,321$ & $-5,389$ & $-1,406$ & 1,585 & 114 & $-4,867$ & 747 & 2,278 \\
\hline
\end{tabular}

Source: See table 2.3.

Note: See table 2.3.

The ISW plays a dual role in the decision. First, higher levels of ISW have wealth effects that cause individuals to retire earlier; more wealth through IS programs will lead to increased consumption of all goods, including leisure. Second, however, higher accruals of ISW from additional work should have a substitution effect that leads to later retirement; if there is a large financial incentive to additional years of work, then individuals will retire later.

Therefore, equations are estimated of the form

(2) $R_{i t}=\delta_{0}+\delta_{1} \mathrm{ISW}_{i t}+\delta_{2} \mathrm{ACC}_{i t}+\delta_{3} \mathrm{AGE}_{i t}+\delta_{4} \mathrm{EARN}_{i t}+\delta_{5} \mathrm{APE}_{i t}+$

$$
\delta_{6} \mathrm{SPEARN}_{i t}+\delta_{7} \mathrm{SPAPE}+\delta_{8} \mathrm{RPP}_{i t}+\delta_{9} X_{i t}+v_{i t} \text {, }
$$

where

- $R_{i t}$ is a variable which equals 1 in the year of retirement and 0 otherwise;

- $\mathrm{ISW}_{i t}$ is the expected PDV of ISW in year $t$;

- $\mathrm{ACC}_{i t}$ is one of the measures of accrual outlined above (the simple one-year accrual, the peak value accrual, or the utility-based option value accrual);

- $\mathrm{AGE}_{i t}$ represents a set of dummy variables for each age in our sample and a measure of the difference in ages across spouses; 


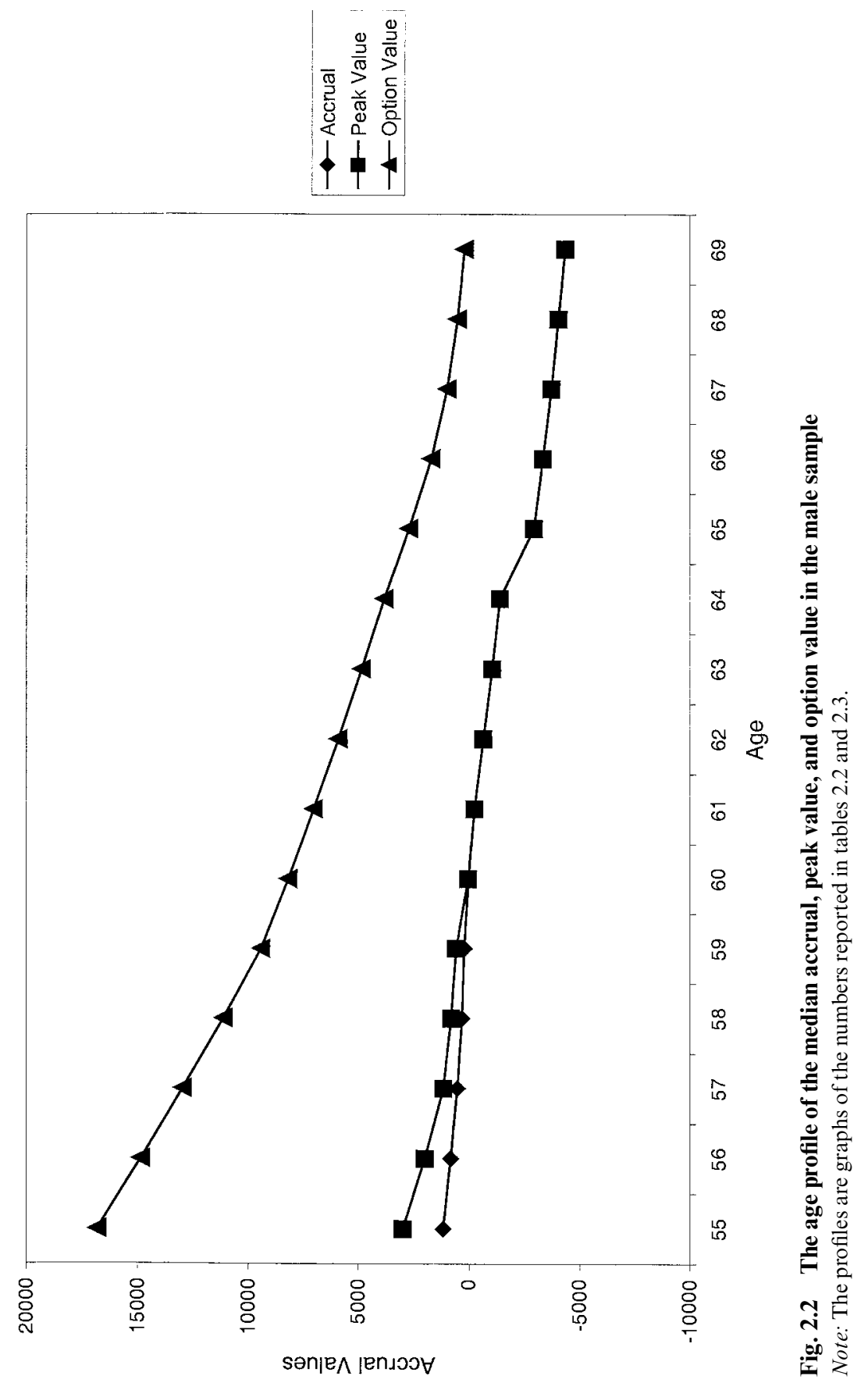




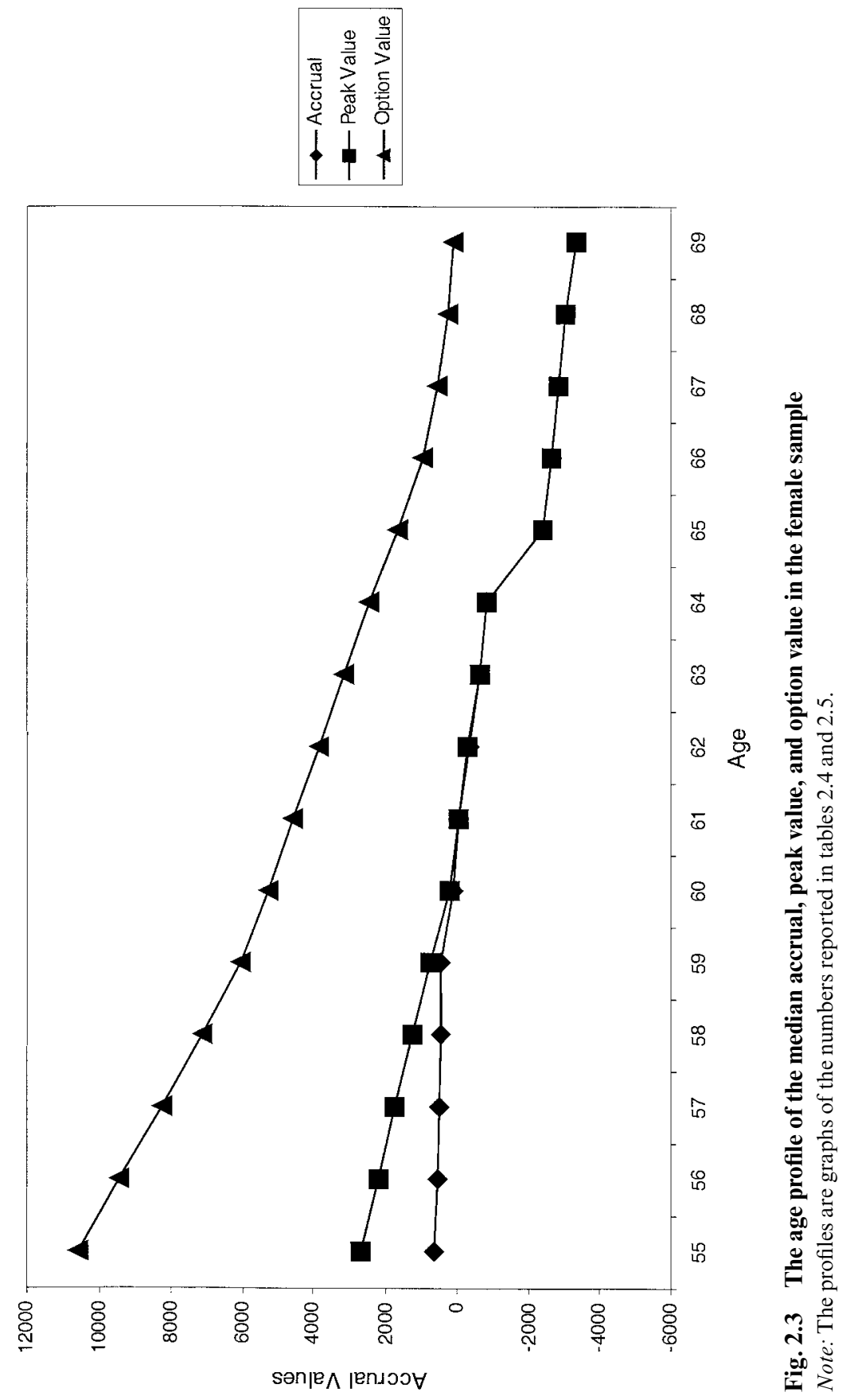


- EARN ${ }_{i t}$ and $\mathrm{APE}_{i t}$ represent cubics in measures of the individual's projected earnings in year $t$ and their APE (for CPP/QPP calculations);

- SPEARN ${ }_{i t}$ and $\mathrm{SPAPE}_{i t}$ are the corresponding variables of any spouse;

- $\mathrm{RPP}_{i t}$ is the measure of the probability of RPP coverage at the 3-digit industry level, ${ }^{32}$

- $X_{i t}$ are a set of additional control variables, including a dummy variable for marital status; a quadratic in tenure on the job and a dummy variable that equals one if tenure is censored at 1978; a quadratic in the individual's and their spouse's labor market experience measured as the number of years of positive T-4 earnings between 1975 and year $t$; eleven industry dummies; and dummies for six categories of establishment size and province and year effects.

To capture potential nonlinear relationships between earnings and retirement decisions, we include a full set of interactions between the cubics in EARN $_{i t}$ and $\mathrm{APE}_{i t}$, and SPEARN $\mathrm{S}_{i t}$ and $\mathrm{SPAPE}_{i t}$. The equations are estimated separately for males and females as a probit.

As mentioned at various points of this discussion, the Canadian IS system went through a number of reforms in our period of analysis. This is a distinct advantage of evaluating the retirement incentives of the Canadian IS system relative to other countries. These policy interventions potentially provide more credible identifying variation for the parameters of the ISW incentive variables than the variation across individuals due to differences in earnings histories, family circumstances, and tastes. This advantage is highlighted in the reforms of the CPP system that do not have a counterpart in the QPP system in the period 1985-1995. In this case, the residents of Quebec provide a control group for the effects of the reform. Of particular importance here is the introduction of early retirement to the CPP system in 1987. A similar reform of the QPP was accomplished in $1984 .{ }^{33}$

\subsubsection{Sample Characteristics}

In tables 2.6 and 2.7, some average demographic and job characteristics for the male and female samples are presented, which are calculated over all the observations. ${ }^{34}$ The average age in our male sample is almost sixty years old. Fifty-six percent of the sample observations are for married men. Average projected earnings for the males are $\$ 19,503$, while the average APE is $\$ 19,847$. The corresponding averages for their spouses are

32. The standard errors here are potentially biased due to a correlation of the error term across individuals within the three-digit industry code (the "grouped data problem"). Correcting for this bias would lead to larger estimated standard errors on the parameter on RPP.

33. Another reform during our sample period is the introduction of the clawback of OAS benefits in 1989. This applied to individuals in all parts of the country.

34. An alternative would be to calculate the means over individuals. 

Summary Statistics for the Male Sample

\begin{tabular}{lrr}
\hline & Mean & SD \\
\hline Retired & 0.148 & 0.355 \\
Probability of RPP & 0.582 & 0.256 \\
Married & 0.558 & 0.497 \\
Tenure & 8.763 & 4.500 \\
Tenure Censored & 0.441 & 0.496 \\
Experience & 15.235 & 5.162 \\
Spouse's Experience & 5.144 & 6.848 \\
Age & 59.779 & 3.375 \\
Age Difference & 2.067 & 3.820 \\
Projected Earnings & $\$ 19,503$ & 29,088 \\
Projected Spousal Earnings & $\$ 3,033$ & 7,732 \\
APE & $\$ 19,847$ & 4,525 \\
Spouse's APE & $\$ 5,393$ & 7,996 \\
No. of observations & 607,329 & \\
No. of individuals & 121,204 & \\
\hline
\end{tabular}

Notes: $\mathrm{SD}=$ standard deviation. The reported statistics are means (averages) calculated over all observations in the male and female datasets, respectively (rather than over all individuals). All dollar values are in 1998 U.S. dollars. Definitions of all variables are provided in the appendix.

Table 2.7

Summary Statistics for the Female Sample

\begin{tabular}{lrr}
\hline & Mean & SD \\
\hline Retired & 0.151 & 0.358 \\
Probability of RPP & 0.428 & 0.262 \\
Married & 0.404 & 0.491 \\
Tenure & 8.660 & 4.423 \\
Tenure Censored & 0.374 & 0.484 \\
Experience & 14.450 & 5.551 \\
Spouse's Experience & 5.279 & 7.187 \\
Age & 59.488 & 3.365 \\
Age Difference & -0.684 & 2.718 \\
Projected Earnings & $\$ 11,458$ & 8,433 \\
Projected Spousal Earnings & $\$ 4,050$ & 12,897 \\
APE & $\$ 13,871$ & 6,924 \\
Spouse's APE & $\$ 7,500$ & 10,189 \\
No. of observations & 389,808 & \\
No. of individuals & 77,845 & \\
\hline
\end{tabular}

Note: See table 2.6 .

$\$ 3,033$ and $\$ 5,393$ respectively. ${ }^{35}$ Finally, the average probability of RPP coverage across observations is 58 percent.

35. Note that the averages for the spouses are much less than the averages for the males. This is part because we calculate these averages over all males, including those who have no spouse or whose spouse does not work. In these cases, spousal earnings will be 0 , thus lowering the average. 
The average age in our female sample is 59.5 years. Both the married and RPP proportions are lower than in the male sample at 0.40 and 0.43 , respectively. Average projected earnings are $\$ 11,458$, while the average APE is $\$ 13,871$. It is interesting to note that these female workers have similar tenure (length of time with the current employer) and experience (number of years in the labor market) as their male counterparts, but this is likely because our measures are only since 1978 (tenure) and 1975 (experience); over the full working life, presumably these means are much lower for women. The reason that the means of spousal earnings are lower than own earnings for women is because average spousal earnings are calculated using zeros for nonmarried working women.

In figures 2.4 and 2.5 , we present estimates of the retirement hazard for males and females in our sample, which is calculated across all birth cohorts in the sample and all years. The hazard for each sex displays a distinct jump at age fifty-nine to sixty, which is the point of first eligibility for CPP/ QPP benefits. This is also the age at which individuals are first eligible for the SPA. It then increases modestly at ages sixty-one through sixty-four. Finally, there is a spike at age sixty-five. Relative to the profile for males, the hazard for females is slightly higher at ages younger than sixty, rises more quickly and higher at fifty-nine to sixty, remains above its male counterpart until age sixty-four, and has a smaller spike at age sixty-five.

\subsubsection{Retirement Regression Results}

In table 2.8 we present our basic regression results. There are three major groupings (represented in columns) corresponding to the three incentive measures used - accrual, peak value, and option value. In the first column of each grouping we report results from the specification that include linear controls for age, while the second column is for the specification that includes age dummies. ${ }^{36}$ Since the coefficients from these probit regressions are difficult to interpret directly, we report the effect of a $\$ 10,000$ change in ISW or a $\$ 1,000$ change in the accrual measure.

Our results are uniformly supportive of an important role for IS incentives in determining retirement. In every column, there is a positive and significant coefficient on ISW, and a negative and significant coefficient on the accrual measure. When age dummies are excluded, we find that a $\$ 10,000$ rise in ISW raises the odds of retirement by 1.4 to 2 percentage points, from a base of 14.8 percent. When age dummies are included, the effect of ISW falls considerably, however, so that a $\$ 10,000$ rise in ISW raises retirement rates by only 0.23 to 0.51 percentage points.

The incentive measure effects also are reduced when age dummies are

36. See Baker, Gruber, and Milligan (2003) for other specifications. Controls for past and current earnings change the magnitude of the estimated parameters substantially. This emphasizes the importance of including rich controls as we do in this chapter. 


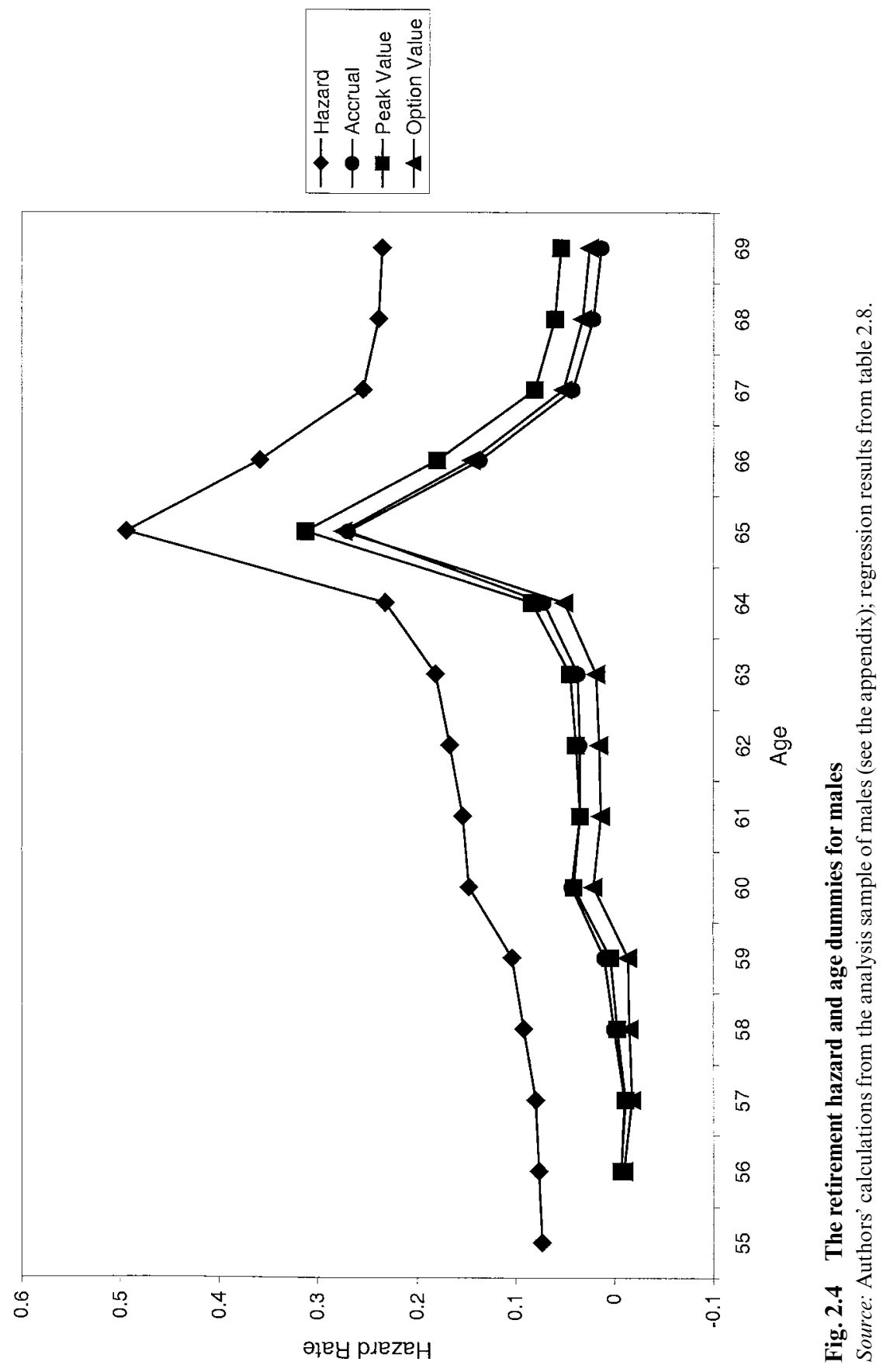




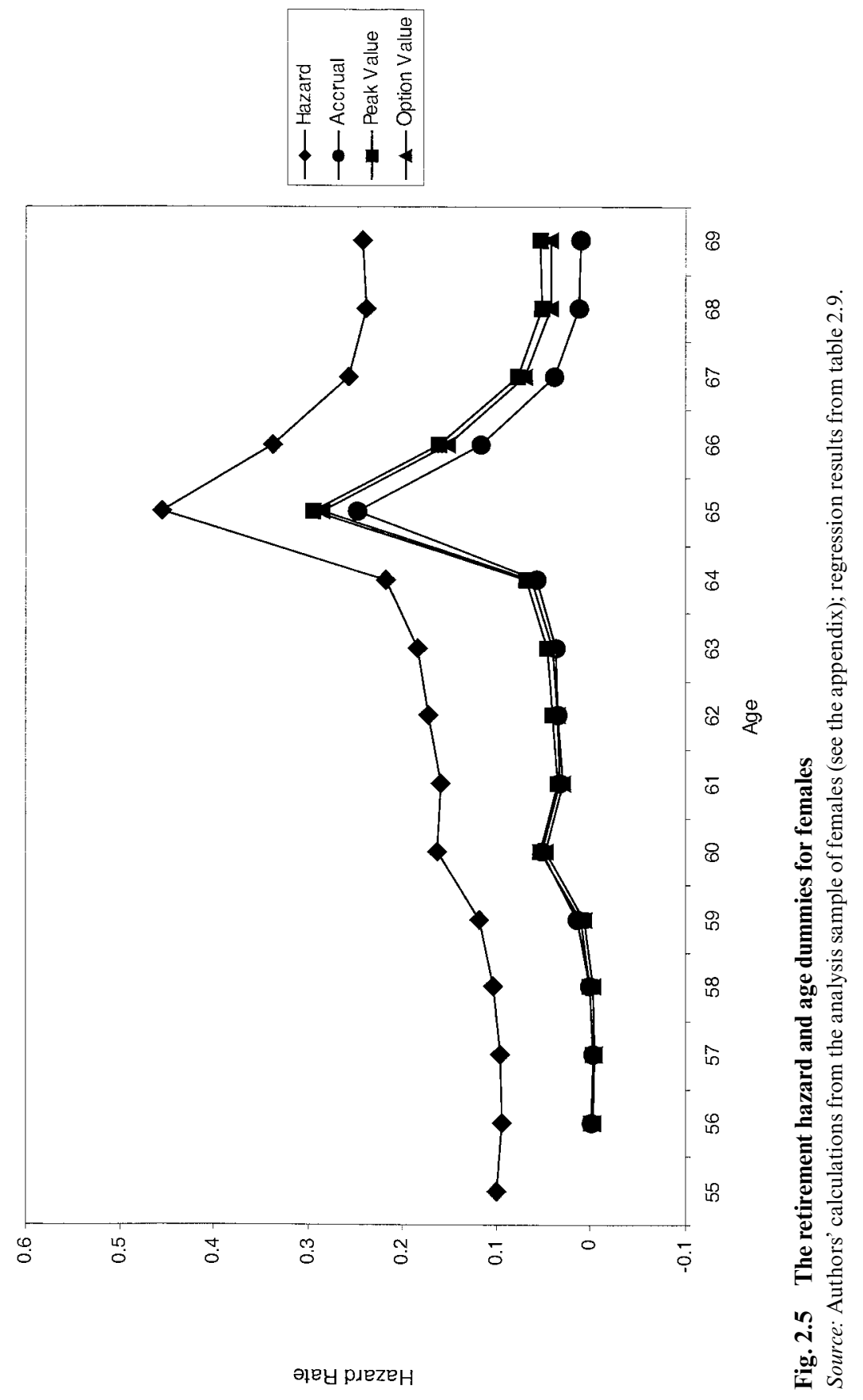


Retirement Probits (male sample)

\begin{tabular}{|c|c|c|c|c|c|c|}
\hline & \multicolumn{2}{|c|}{ Accrual Model } & \multicolumn{2}{|c|}{ Peak Value Model } & \multicolumn{2}{|c|}{ Option Value Model } \\
\hline & $\begin{array}{l}\text { Linear } \\
\text { Age }\end{array}$ & $\begin{array}{c}\text { Age } \\
\text { Dummies }\end{array}$ & $\begin{array}{l}\text { Linear } \\
\text { Age }\end{array}$ & $\begin{array}{c}\text { Age } \\
\text { Dummies }\end{array}$ & $\begin{array}{l}\text { Linear } \\
\text { Age }\end{array}$ & $\begin{array}{c}\text { Age } \\
\text { Dummies }\end{array}$ \\
\hline ISW & $\begin{array}{c}0.093 \\
(0.003)\end{array}$ & $\begin{array}{c}0.025 \\
(0.004)\end{array}$ & $\begin{array}{c}0.077 \\
(0.003)\end{array}$ & $\begin{array}{c}0.022 \\
(0.004)\end{array}$ & $\begin{array}{c}0.067 \\
(0.004)\end{array}$ & $\begin{array}{c}0.012 \\
(0.004)\end{array}$ \\
\hline$\$ 10,000$ change & 1.97 & 0.51 & 1.60 & 0.45 & 1.38 & 0.23 \\
\hline ACCRUAL & $\begin{array}{l}-1.183 \\
(0.023)\end{array}$ & $\begin{array}{c}-0.798 \\
(0.028)\end{array}$ & $\begin{array}{c}-0.577 \\
(0.017)\end{array}$ & $\begin{array}{c}-0.345 \\
(0.018)\end{array}$ & $\begin{array}{l}-0.284 \\
(0.011)\end{array}$ & $\begin{array}{l}-0.315 \\
(0.009)\end{array}$ \\
\hline$\$ 1,000$ change & -2.21 & -1.52 & -1.11 & -0.67 & -0.56 & -0.61 \\
\hline RPP & $\begin{array}{c}0.125 \\
(0.013)\end{array}$ & $\begin{array}{c}0.123 \\
(0.013)\end{array}$ & $\begin{array}{c}0.124 \\
(0.013)\end{array}$ & $\begin{array}{c}0.123 \\
(0.013)\end{array}$ & $\begin{array}{c}0.124 \\
(0.013)\end{array}$ & $\begin{array}{c}0.126 \\
(0.013)\end{array}$ \\
\hline MARRIED & $\begin{array}{c}-0.539 \\
(0.020)\end{array}$ & $\begin{array}{c}-0.182 \\
(0.022)\end{array}$ & $\begin{array}{c}-0.454 \\
(0.020)\end{array}$ & $\begin{array}{c}-0.173 \\
(0.022)\end{array}$ & $\begin{array}{c}-0.411 \\
(0.021)\end{array}$ & $\begin{array}{l}-0.110 \\
(0.023)\end{array}$ \\
\hline TENURE & $\begin{array}{c}-0.029 \\
(0.002)\end{array}$ & $\begin{array}{c}-0.031 \\
(0.002)\end{array}$ & $\begin{array}{c}-0.034 \\
(0.002)\end{array}$ & $\begin{array}{c}-0.033 \\
(0.002)\end{array}$ & $\begin{array}{c}-0.030 \\
(0.002)\end{array}$ & $\begin{array}{c}-0.029 \\
(0.002)\end{array}$ \\
\hline TENURESQ & $\begin{array}{c}0.002 \\
(0.0001)\end{array}$ & $\begin{array}{c}0.002 \\
(0.0001)\end{array}$ & $\begin{array}{c}0.002 \\
(0.0001)\end{array}$ & $\begin{array}{c}0.002 \\
(0.0001)\end{array}$ & $\begin{array}{c}0.002 \\
(0.0001)\end{array}$ & $\begin{array}{c}0.002 \\
(0.0001)\end{array}$ \\
\hline TENURE CENS & $\begin{array}{c}0.026 \\
(0.006)\end{array}$ & $\begin{array}{c}0.026 \\
(0.007)\end{array}$ & $\begin{array}{c}0.028 \\
(0.006)\end{array}$ & $\begin{array}{c}0.027 \\
(0.007)\end{array}$ & $\begin{array}{c}0.034 \\
(0.006)\end{array}$ & $\begin{array}{c}0.032 \\
(0.007)\end{array}$ \\
\hline EXP & $\begin{array}{c}-0.022 \\
(0.002)\end{array}$ & $\begin{array}{l}-0.020 \\
(0.002)\end{array}$ & $\begin{array}{l}-0.018 \\
(0.002)\end{array}$ & $\begin{array}{c}-0.018 \\
(0.002)\end{array}$ & $\begin{array}{c}-0.014 \\
(0.002)\end{array}$ & $\begin{array}{c}-0.015 \\
(0.002)\end{array}$ \\
\hline EXP SQ & $\begin{array}{c}0.000 \\
(0.0001)\end{array}$ & $\begin{array}{c}0.000 \\
(0.0004)\end{array}$ & $\begin{array}{l}0.000 \\
(0.0001)\end{array}$ & $\begin{array}{c}0.000 \\
(0.0001)\end{array}$ & $\begin{array}{c}0.0000 \\
(0.0001)\end{array}$ & $\begin{array}{c}0.000 \\
(0.0001)\end{array}$ \\
\hline SPOUSE EXP & $\begin{array}{c}-0.027 \\
(0.003)\end{array}$ & $\begin{array}{c}-0.028 \\
(0.001)\end{array}$ & $\begin{array}{c}-0.029 \\
(0.003)\end{array}$ & $\begin{array}{c}-0.029 \\
(0.003)\end{array}$ & $\begin{array}{c}-0.027 \\
(0.003)\end{array}$ & $\begin{array}{c}-0.028 \\
(0.003)\end{array}$ \\
\hline SPOUSE EXPSQ & $\begin{array}{c}0.001 \\
(0.0001)\end{array}$ & $\begin{array}{c}0.001 \\
(0.0001)\end{array}$ & $\begin{array}{c}0.001 \\
(0.0001)\end{array}$ & $\begin{array}{c}0.001 \\
(0.0001)\end{array}$ & $\begin{array}{c}0.001 \\
(0.0001)\end{array}$ & $\begin{array}{c}0.001 \\
(0.0001)\end{array}$ \\
\hline AGE & $\begin{array}{c}0.013 \\
(0.001)\end{array}$ & & $\begin{array}{c}0.033 \\
(0.001)\end{array}$ & & $\begin{array}{c}0.039 \\
(0.001)\end{array}$ & \\
\hline AGEDIFF & $\begin{array}{c}0.003 \\
(0.001)\end{array}$ & $\begin{array}{c}-0.003 \\
(0.001)\end{array}$ & $\begin{array}{c}0.001 \\
(0.001)\end{array}$ & $\begin{array}{c}-0.003 \\
(0.001)\end{array}$ & $\begin{array}{c}-0.001 \\
(0.001)\end{array}$ & $\begin{array}{c}-0.004 \\
(0.001)\end{array}$ \\
\hline AGE56 & & $\begin{array}{c}-0.036 \\
(0.011)\end{array}$ & & $\begin{array}{c}-0.036 \\
(0.011)\end{array}$ & & $\begin{array}{c}-0.050 \\
(0.011)\end{array}$ \\
\hline AGE57 & & $\begin{array}{c}-0.053 \\
(0.011)\end{array}$ & & $\begin{array}{c}-0.059 \\
(0.012)\end{array}$ & & $\begin{array}{l}-0.095 \\
(0.012)\end{array}$ \\
\hline AGE58 & & $\begin{array}{c}0.002 \\
(0.012)\end{array}$ & & $\begin{array}{l}-0.015 \\
(0.012)\end{array}$ & & $\begin{array}{c}-0.079 \\
(0.012)\end{array}$ \\
\hline AGE59 & & $\begin{array}{c}0.050 \\
(0.012)\end{array}$ & & $\begin{array}{c}0.021 \\
(0.012)\end{array}$ & & $\begin{array}{l}-0.071 \\
(0.013)\end{array}$ \\
\hline AGE60 & & $\begin{array}{c}0.199 \\
(0.012)\end{array}$ & & $\begin{array}{c}0.189 \\
(0.013)\end{array}$ & & $\begin{array}{c}0.101 \\
(0.013)\end{array}$ \\
\hline AGE61 & & $\begin{array}{c}0.162 \\
(0.014)\end{array}$ & & $\begin{array}{c}0.162 \\
(0.14)\end{array}$ & & $\begin{array}{c}0.066 \\
(0.014)\end{array}$ \\
\hline AGE62 & & $\begin{array}{c}0.162 \\
(0.015)\end{array}$ & & $\begin{array}{c}0.179 \\
(0.015)\end{array}$ & & $\begin{array}{c}0.074 \\
(0.015)\end{array}$ \\
\hline AGE63 & & $\begin{array}{c}0.171 \\
(0.016)\end{array}$ & & $\begin{array}{c}0.203 \\
(0.016)\end{array}$ & & $\begin{array}{c}0.089 \\
(0.016)\end{array}$ \\
\hline
\end{tabular}

(continued) 
Table 2.8 (continued)

\begin{tabular}{|c|c|c|c|c|c|c|}
\hline & \multicolumn{2}{|c|}{ Accrual Model } & \multicolumn{2}{|c|}{ Peak Value Model } & \multicolumn{2}{|c|}{ Option Value Model } \\
\hline & $\begin{array}{l}\text { Linear } \\
\text { Age }\end{array}$ & $\begin{array}{c}\text { Age } \\
\text { Dummies }\end{array}$ & $\begin{array}{c}\text { Linear } \\
\text { Age }\end{array}$ & $\begin{array}{c}\text { Age } \\
\text { Dummies }\end{array}$ & $\begin{array}{c}\text { Linear } \\
\text { Age }\end{array}$ & $\begin{array}{c}\text { Age } \\
\text { Dummies }\end{array}$ \\
\hline AGE64 & & $\begin{array}{c}0.309 \\
(0.017)\end{array}$ & & $\begin{array}{c}0.353 \\
(0.017)\end{array}$ & & $\begin{array}{c}0.227 \\
(0.018)\end{array}$ \\
\hline AGE65 & & $\begin{array}{c}0.914 \\
(0.020)\end{array}$ & & $\begin{array}{c}1.028 \\
(0.019)\end{array}$ & & $\begin{array}{c}0.928 \\
(0.019)\end{array}$ \\
\hline AGE66 & & $\begin{array}{c}0.527 \\
(0.021)\end{array}$ & & $\begin{array}{c}0.658 \\
(0.021)\end{array}$ & & $\begin{array}{c}0.555 \\
(0.020)\end{array}$ \\
\hline AGE67 & & $\begin{array}{c}0.190 \\
(0.024)\end{array}$ & & $\begin{array}{c}0.338 \\
(0.023)\end{array}$ & & $\begin{array}{c}0.229 \\
(0.022)\end{array}$ \\
\hline AGE68 & & $\begin{array}{c}0.100 \\
(0.025)\end{array}$ & & $\begin{array}{c}0.262 \\
(0.024)\end{array}$ & & $\begin{array}{c}0.148 \\
(0.024)\end{array}$ \\
\hline AGE69 & & $\begin{array}{c}0.063 \\
(0.027)\end{array}$ & & $\begin{array}{c}0.238 \\
(0.026)\end{array}$ & & $\begin{array}{c}0.118 \\
(0.025)\end{array}$ \\
\hline Pseudo $R^{2}$ & 0.103 & 0.116 & 0.100 & 0.115 & 0.099 & 0.116 \\
\hline OTHER CONTROLS & Yes & Yes & Yes & Yes & Yes & Yes \\
\hline
\end{tabular}

Notes: AGEDIFF (the difference in ages between the individual and his spouse) is coded 0 for singles. The statistics reported in the rows " $\$ 10,000$ change" and " $\$ 1,000$ change" are the percentage point change in the probability of retirement for the indicated change in ISW or accrual. Other control variables are 11 industry dummies; dummies for 6 categories of establishment size; province and year effects; a cubic in both own and spouse's predicted earnings and APE; and a full set of interactions between these cubics. The estimated parameters on these additional variables are not reported. Standard errors are in parentheses.

included, but they are less sensitive than is ISW. For the one-year accrual, we find that a $\$ 1,000$ rise leads to a 2.21 percentage point decline in retirement without age dummies and a 1.52 percentage point decline with age dummies. The effects of a change in peak value are roughly half as large. The effects of option value, a 0.6 percentage point decline in retirement for a $\$ 1,000$ increase, are essentially invariant to the inclusion of age dummies.

The control variables themselves have their expected signs. Of particular interest is that the effect of our measure of RPP-coverage probability is positive and statistically significant. This is consistent with a wealth effect as result of the additional savings represented by the RPP entitlement. Marriage and larger age differences (Agediff) between spouses have a negative relationship with the probability of retirement. Conditional on age, both experience and tenure reduce the probability of retirement, although in each case at a decreasing rate. Older men are more likely to retire. There is a clear pattern of highly significant age dummies from age sixty onwards.

The estimates of the year effects (not reported) reveal that most of the time effects are cyclical. Also, the probability of retirement displays a vague $\mathrm{U}$ shape with establishment size: larger probabilities in the smallest and 
largest establishments. The higher probability of retirement in the largest establishments may be partly an (unobserved) RPP effect.

It is important to note that the ISW and accrual variables may not fully capture the impacts of the IS system. This is illustrated in figures 2.4 and 2.5 , in which we report the baseline retirement hazard, along with the estimated pattern of age dummies, from our three different models that include age dummies. ${ }^{37}$ What is immediately apparent is that while the IS variables in our model account for some of the age effects in the hazard, the basic profile of the effects is still very evident. There are two conclusions one can draw from this observation. The first is that we have fully captured the impact of the IS system on behavior, and the age-specific pattern of retirement that remains is due to nonlinear changes in the taste for leisure with age or institutions, such as mandatory retirement, that are not otherwise captured in our model. The second is that the spike at age sixty-five is capturing the more fundamental aspects of the response to the IS system that are not captured by our regressors, so that we are underestimating the full impact of the system on retirement decisions. As we discuss below, which interpretation is correct has important implications for assessing the policy implications of our findings.

Table 2.9 and figure 2.5 contain parallel results for women. The findings for ISW and for one-year accrual are remarkably similar to those for men. This is striking and may suggest that, conditional on being in the labor force at older ages, women can be viewed as responding to financial incentives in the same way as do men. This finding is consistent with Coile's (1999) findings for the United States. The effects are a bit smaller for women, however, for the peak and option value measures.

\subsection{Policy Simulations}

The preceding results are difficult to interpret in a vacuum. Thus, for both evaluation and comparison with the other results in this volume, we consider the implications of our findings for two significant reforms to the Canadian system. The first is an increase of three years in the age of both early and normal entitlement for IS programs, holding all other aspects of the system constant. The second is a shift to a new, simpler system that features only one program and has an early retirement age of sixty and a normal retirement age of sixty-five. This system provides for all persons, at age sixty-five, a benefit equal to 60 percent of their projected age sixty earnings; we use projected earnings so that we have a value even for those who retire before age sixty. There is an actuarial reduction of 6 percent per year for

37. The age dummies are constructed as the incremental probability implied by the probit coefficient for each age. The probability is calculated at the mean of the other variables. 


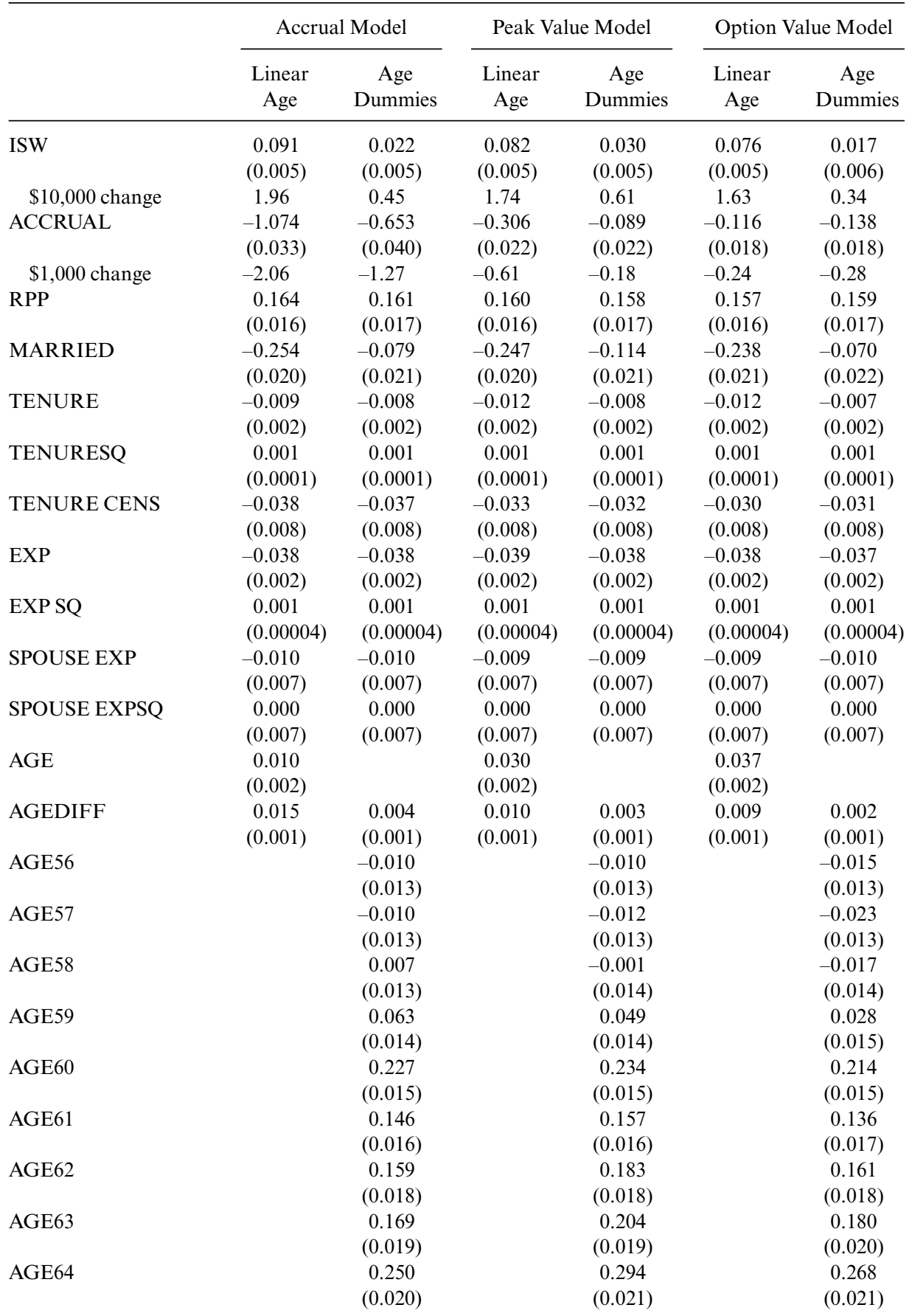


(continued)

\begin{tabular}{|c|c|c|c|c|c|c|}
\hline & \multicolumn{2}{|c|}{ Accrual Model } & \multicolumn{2}{|c|}{ Peak Value Model } & \multicolumn{2}{|c|}{ Option Value Model } \\
\hline & $\begin{array}{l}\text { Linear } \\
\text { Age }\end{array}$ & $\begin{array}{c}\text { Age } \\
\text { Dummies }\end{array}$ & $\begin{array}{l}\text { Linear } \\
\text { Age }\end{array}$ & $\begin{array}{c}\text { Age } \\
\text { Dummies }\end{array}$ & $\begin{array}{l}\text { Linear } \\
\text { Age }\end{array}$ & $\begin{array}{c}\text { Age } \\
\text { Dummies }\end{array}$ \\
\hline AGE65 & & $\begin{array}{c}0.844 \\
(0.023)\end{array}$ & & $\begin{array}{c}0.970 \\
(0.022)\end{array}$ & & $\begin{array}{c}0.947 \\
(0.022)\end{array}$ \\
\hline AGE66 & & $\begin{array}{l}0.456 \\
(0.025)\end{array}$ & & $\begin{array}{l}0.598 \\
(0.024)\end{array}$ & & $\begin{array}{c}0.572 \\
(0.024)\end{array}$ \\
\hline AGE67 & & $\begin{array}{c}0.169 \\
(0.028)\end{array}$ & & $\begin{array}{c}0.324 \\
(0.027)\end{array}$ & & $\begin{array}{c}0.292 \\
(0.027)\end{array}$ \\
\hline AGE68 & & $\begin{array}{c}0.053 \\
(0.030)\end{array}$ & & $\begin{array}{c}0.222 \\
(0.029)\end{array}$ & & $\begin{array}{c}0.184 \\
(0.029)\end{array}$ \\
\hline AGE69 & & 0.046 & & 0.232 & & 0.188 \\
\hline $\begin{array}{l}\text { Pseudo } R^{2} \\
\text { OTHER CONTROLS }\end{array}$ & $\begin{array}{c}0.107 \\
\text { Yes }\end{array}$ & $\begin{array}{c}0.117 \\
\text { Yes }\end{array}$ & $\begin{array}{c}0.104 \\
\text { Yes }\end{array}$ & $\begin{array}{c}0.116 \\
\text { Yes }\end{array}$ & $\begin{array}{c}0.104 \\
\text { Yes }\end{array}$ & $\begin{array}{c}0.116 \\
\text { Yes }\end{array}$ \\
\hline
\end{tabular}

Note: See table 2.8 .

early claiming and an actuarial increase of 6 percent per year for later claiming.

For each reform, we consider nine different simulations: There are three simulation approaches for each of the three incentive measures (accrual, peak value, and option value). The first simulation approach (which we label "S1") uses the estimates from the model estimated with a linear control for age. In this case, the simulation operates by incrementing the incentive measures only according to the policy change. Thus, we simply recompute IS wealth at each age under these new rules, and then predict retirement rates by applying these new ISW and accrual values to our estimated coefficients.

The second simulation approach (we label "S2") is the same as the first, but it uses the model with age dummies included. The difference between these approaches is highlighted by the dramatic reduction in the ISW coefficient when the linear age term is replaced by age dummies. There are two possible reasons for this reduction. The first is that tastes for leisure do not increase linearly with age and that the age dummies more appropriately pick up the nonlinearities. Since ISW is nonlinear in a corresponding manner with age, the inclusion of age dummies reduces the coefficient significantly. Alternatively, the age dummies could pick up the effects of other institutions, such as RPPs or mandatory retirement, in certain sectors. The second possibility, however, is that the jump in retirement at age sixty-five is due to the IS system itself, and not inherent tastes for leisure, so that including age dummies, to some extent, robs the ISW term of its true explanatory value. 
Average Retirement Rates in Simulations

\begin{tabular}{lcc}
\hline & \multicolumn{2}{c}{ Simulated Reform } \\
\cline { 2 - 3 } & Plus Three Years & Common System \\
\hline & Males & \\
Base retirement rate & 0.150 & 0.150 \\
Accrual & 0.096 & 0.326 \\
S1 & 0.125 & 0.200 \\
S2 & 0.105 & 0.174 \\
S3 & & \\
Peak value & 0.104 & 0.293 \\
S1 & 0.129 & 0.188 \\
S2 & 0.105 & 0.158 \\
S3 & & \\
Option value & 0.114 & 0.264 \\
S1 & 0.133 & 0.176 \\
S2 & 0.112 & 0.152 \\
S3 & Females & \\
& 0.151 & 0.151 \\
Base retirement rate & & \\
Accrual & 0.107 & 0.222 \\
S1 & 0.134 & 0.160 \\
S2 & 0.119 & 0.143 \\
S3 & &
\end{tabular}

We are statistically unable to distinguish these views, and the $\mathrm{S} 2$ approach errs on the side of the first explanation (nonlinear tastes for leisure) over the second (IS-related, nonlinear age effects). Thus, we also pursue a third simulation (S3) approach using the model with age dummies, but incrementing the age dummies at ages sixty and older by three years for the first policy change. That is, we not only recompute the values of our IS measures arising from the change, but we also recompute the value of the age dummies themselves, so that the age-sixty dummy takes on the estimated value of the age-sixty-three dummy, the age-sixty-one dummy takes on the estimated value of the age-sixty-four dummy, and so forth. This approach errs on the side of the second explanation by attributing all of the age dummy effects to the IS system. Clearly, the truth will be between these two extremes.

We present the results of these eighteen simulations in three forms. First, in table 2.10, we show the effects of each reform on average retirement rates in our sample. Then, in each of the figures 2.6-2.17 we show the impact of each reform on hazard rates and then on the cumulative probability of retirement, each relative to the relevant model's predicted baseline. We estimate all eighteen models for men; for women, we just present the results from the accrual models.

Our findings suggest that these reforms would have very significant impacts on the retirement decisions of older Canadians. Starting with the first 
A

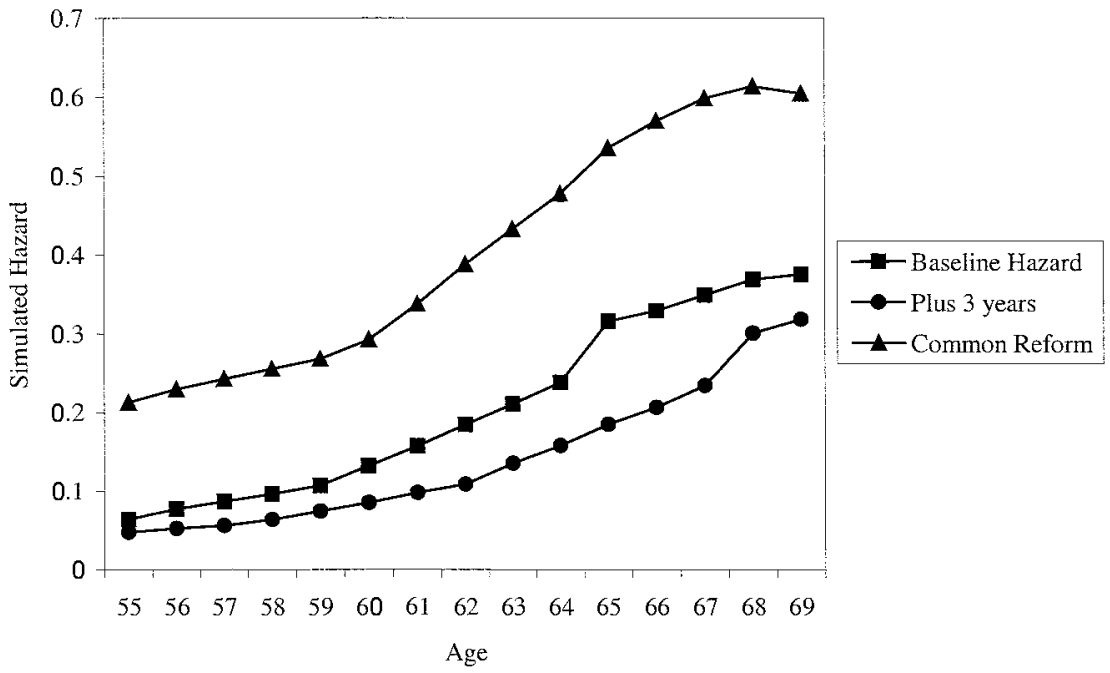

B

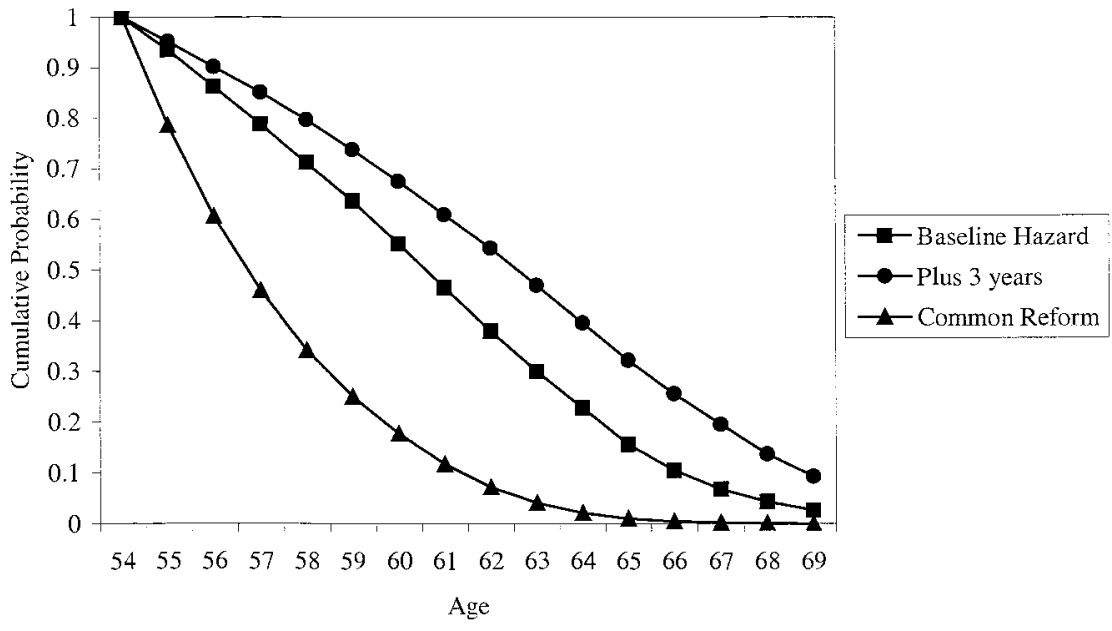

Fig. 2.6 S1 on males using accrual estimates: $A$, Simulated hazard; $B$, Cumulative probability

reform, we find that there is a substantial reduction in retirement when the early and normal eligibility ages are increased. For example, in table 2.10 the average retirement rate is lower regardless of the simulation method or model specification. The reduction ranges between 11 percent (option value, model S2) and 36 percent (accrual value, model S1). The pattern of results is fairly similar across the three types of accrual measures, although the largest effects are for the accrual measure and the smallest are for option value. Comparing across the three simulation methods, we find the 
A

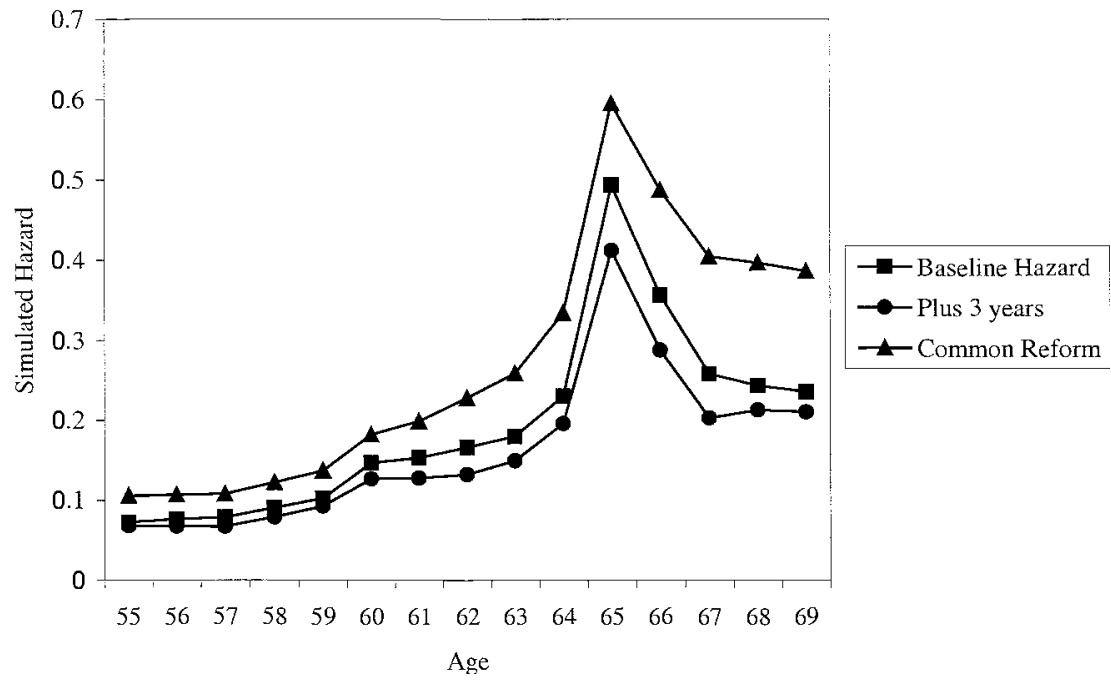

B

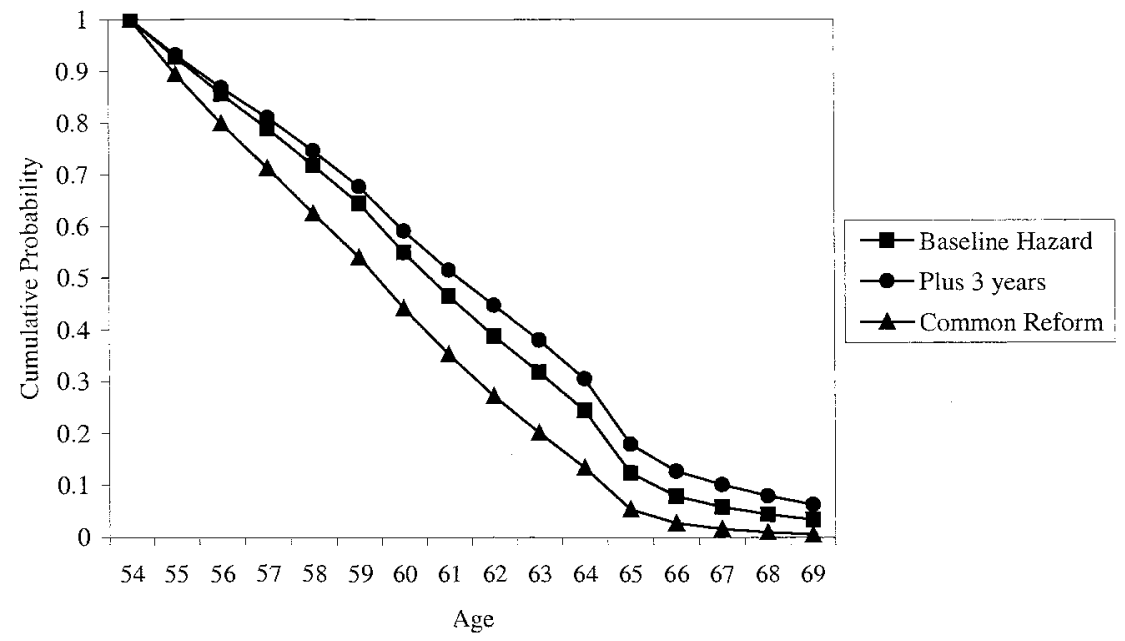

Fig. 2.7 $\mathrm{S} 2$ on males using accrual estimates: $A$, Simulated hazard; $B$, Cumulative probability

largest effects from model S1, which yields findings very close to model S3, and the results are significantly mitigated under model S2. Thus, either controlling linearly for age or assuming that the age dummies capture IS effects yields similar results.

The distribution of the changes across the age profile is revealed in figures 2.6 through 2.17. With the accrual model, regardless of the simulation method, much of the reduction in retirement occurs in the years just before the new normal retirement age of sixty-eight. For example, in figure 2.6, 
A

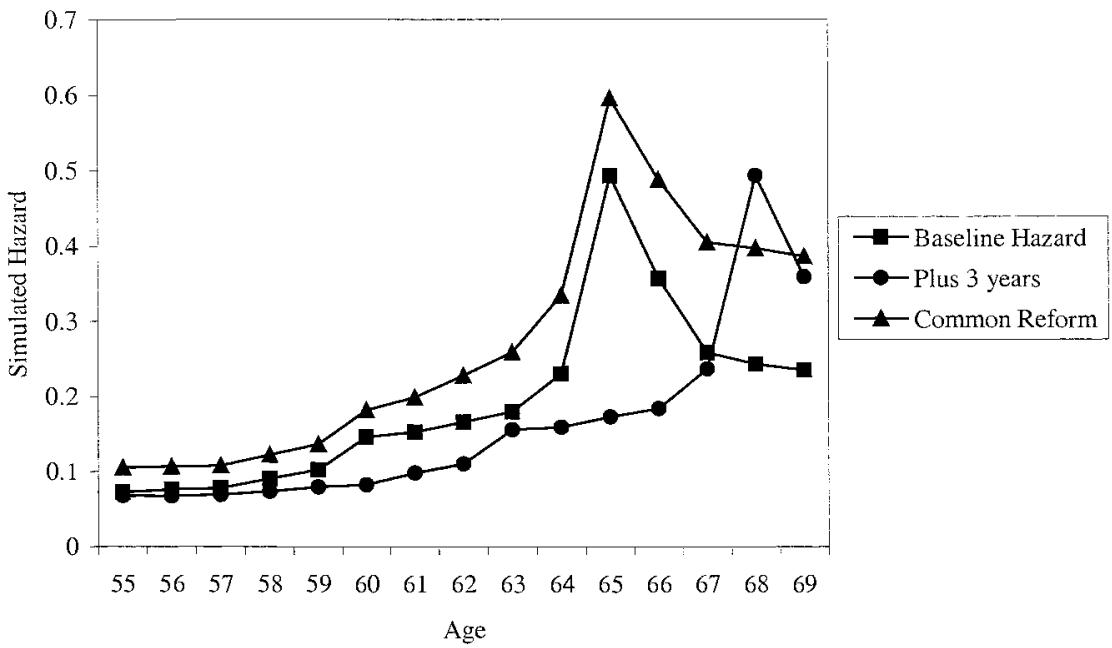

B

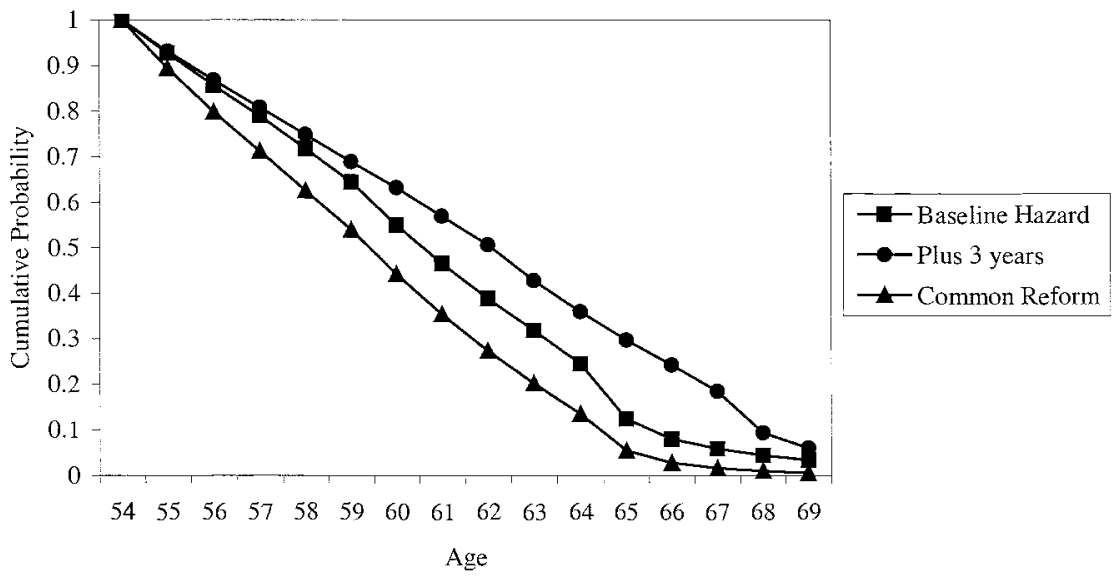

Fig. 2.8 S3 on males using accrual estimates: $A$, Simulated hazard; $B$, Cumulative probability

panel A, the jump in the baseline hazard at age sixty-five shifts over to age sixty-eight under the reform, although there are also sizable reductions in the hazard at earlier ages. In figures 2.7 and 2.8, panels $\mathrm{A}$, the fall in the hazard is even more concentrated at ages sixty-four through sixty-seven. The smaller overall impact of the reform under S2 would appear to result from the greater congruence of the baseline and simulated hazards at earlier ages and the strong reduction in the hazard at age sixty-five. The agesixty-five spike in the hazard remains under the reform because we do not shift the age dummies. Therefore, much of the strength of this reform would appear to result from the change in behavior between the old and 
A

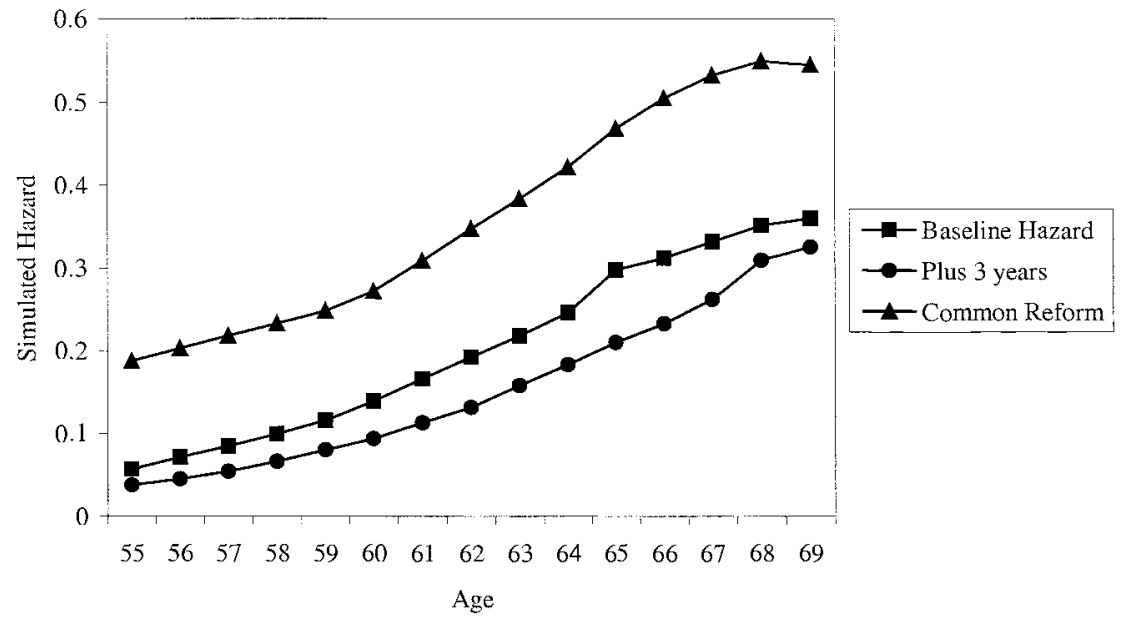

B

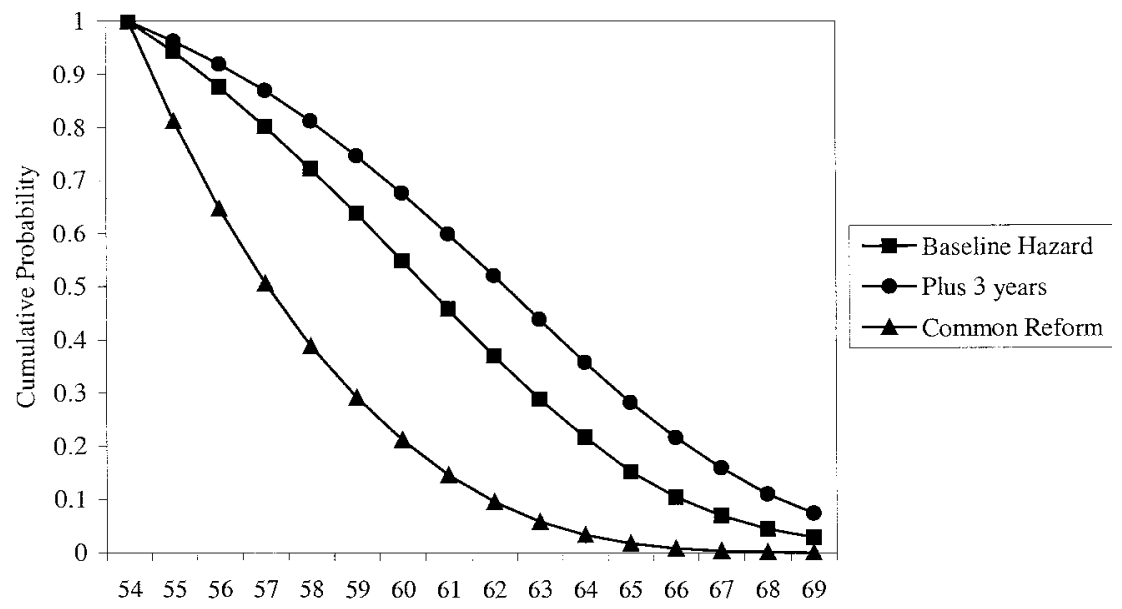

Fig. 2.9 S1 on males using peak value estimates: $A$, Simulated hazard; $B$, Cumulative probability

new normal retirement ages. Other than that, the reform leads to a simple shift out in the cumulative density over the retirement interval (sixty to sixty-nine) suggesting that the same incentives at work on a higher base. A very similar story is told in the results for females (figures 2.15-2.17).

The peak value model simulations reveal a similar story in $\mathrm{S} 1$ (figure 2.9, panel A), but in S2, the reduction in the hazard appears more evenly distributed across ages sixty through sixty-six. Again, with the peak value model, the sharp shift to the right in the hazard in S3 (figure 2.10, panel A) is a result of the shifting of the age dummies. Using the option value model, the effects are similar in direction, but more modest in magnitude. This re- 
A

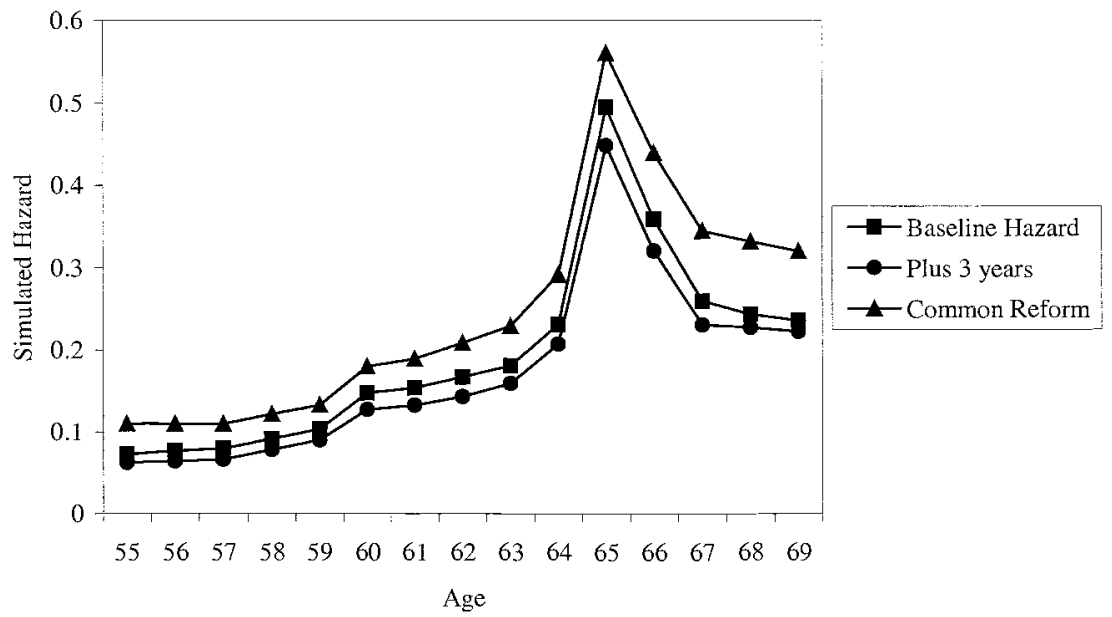

B

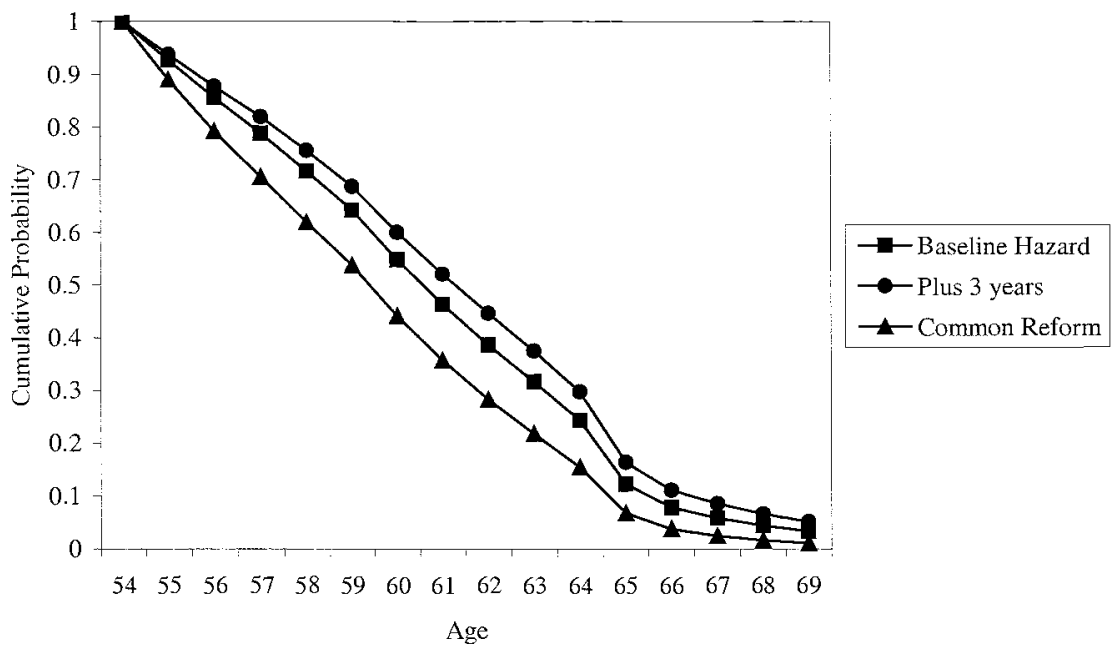

Fig. 2.10 S2 on males using peak value estimates: $A$, Simulated hazard; $B$, Cumulative probability

flects the smaller estimated coefficients for the incentive variables in the option value regressions.

This evidence, therefore, suggests that a reform to change eligibility ages could have a very large impact on retirement rates under the Canadian IS system. However, the size of the shift in the predicted hazards depends strongly on whether one assumes the age dummies should or should not be shifted.

The second reform, moving to a single program with program parameters very similar to the CPP/QPP, has just the opposite effect on average re- 
A

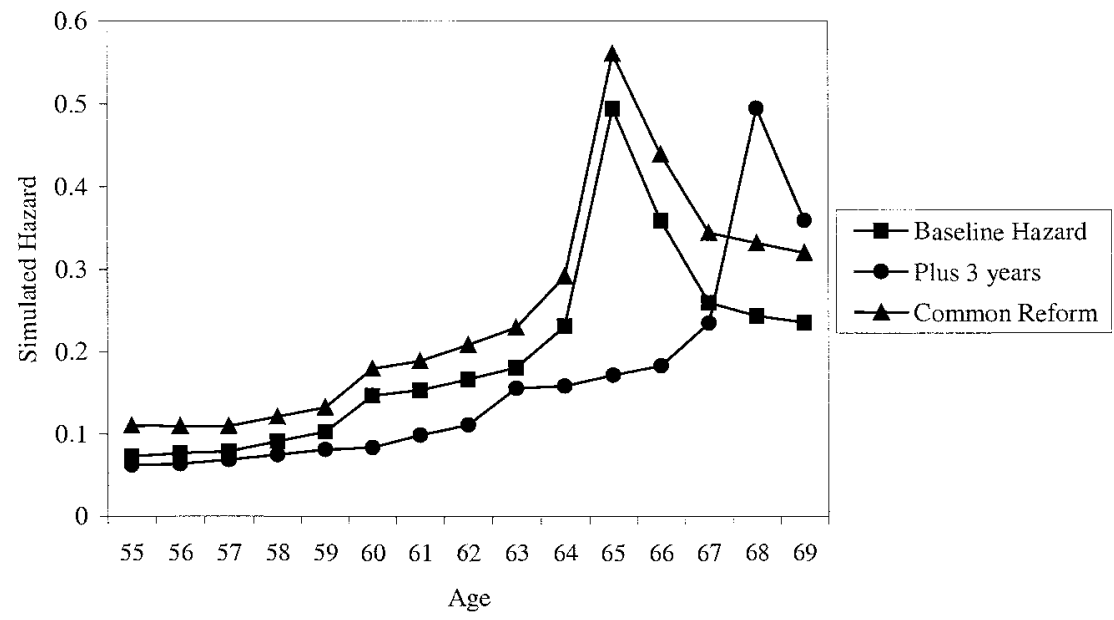

B

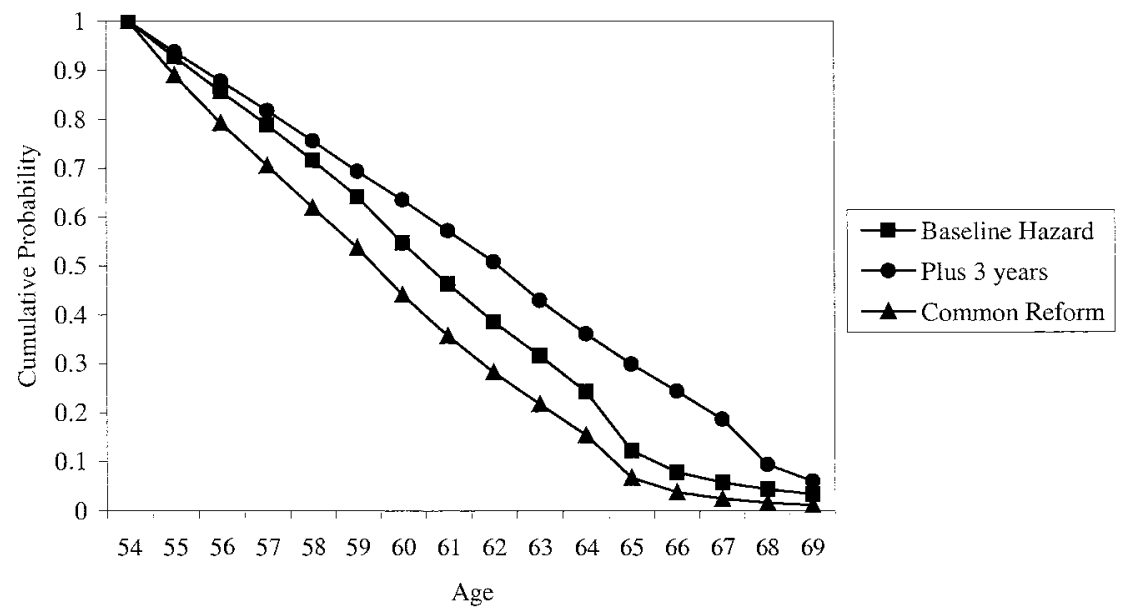

Fig. 2.11 S3 on males using peak value estimates: $A$, Simulated hazard; $B$, Cumulative probability

tirement rates (table 2.10): They increase. The effects here are much more sensitive to the simulation approach employed. For model S1, the retirement rate more than doubles using the one-year accrual model and almost doubles in the peak value and option value models. For models S2 or S3, however, the effects are much more modest, with roughly a 20 percent rise in retirement under model S2 and only about 10 percent under S3.

There are at least two effects at work here. First the levels of ISW are uniformly higher under the reform. Since ISW is positively related to retirement this would raise retirement rates at all ages. The second is that accrual effects arising, for example, from the actuarial adjustment of benefits, are 
A

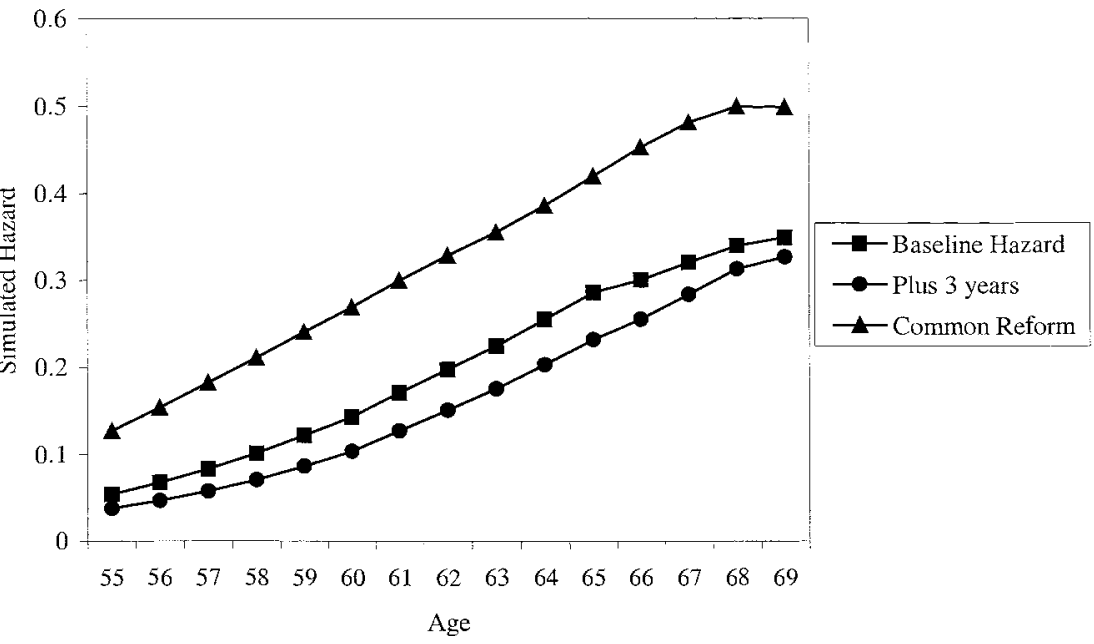

B

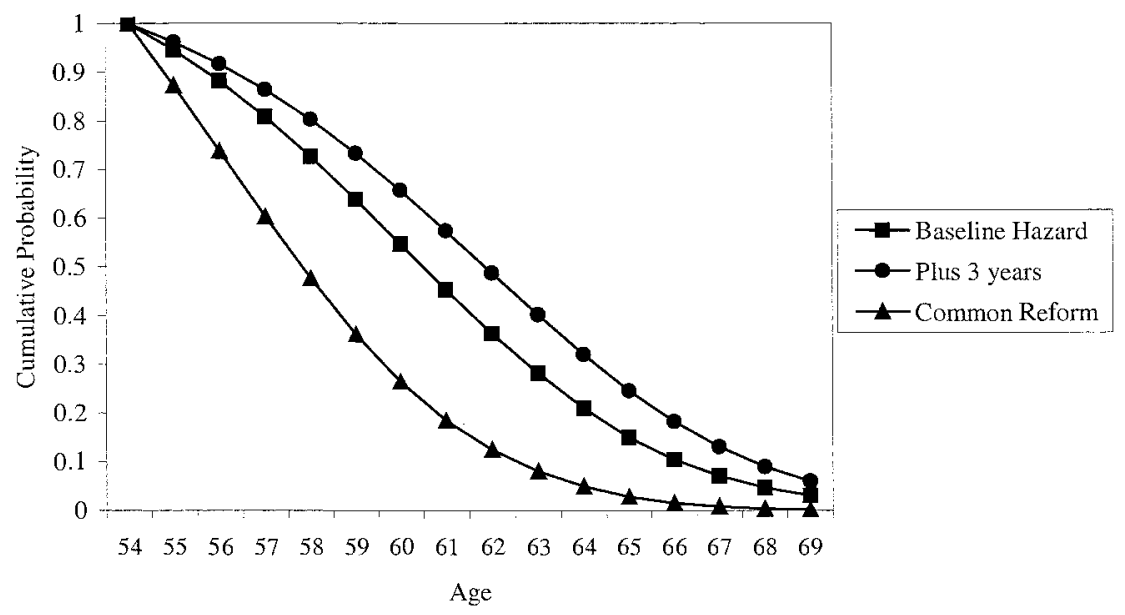

Fig. 2.12 S1 on males using option value estimates: $A$, Simulated hazard; $B$, Cumulative probability

potentially stronger here as they apply to the entire benefit (recall that in the current system these only arise for the CPP/QPP component of the total retirement benefit). At the median, this will lead to larger negative accruals after age sixty than is the case under the current system, which will also increase the hazard at these ages.

Again the figures provide the details. Regardless of the model used, in S1 there are enormous increases in the retirement hazard at all ages. In each case the entire age profile of the hazard shifts upwards 0.1 or more. The shifts in the hazards in S2 and S3 are far more modest, although the wide distribution of the effect across the age profile remains. 
A

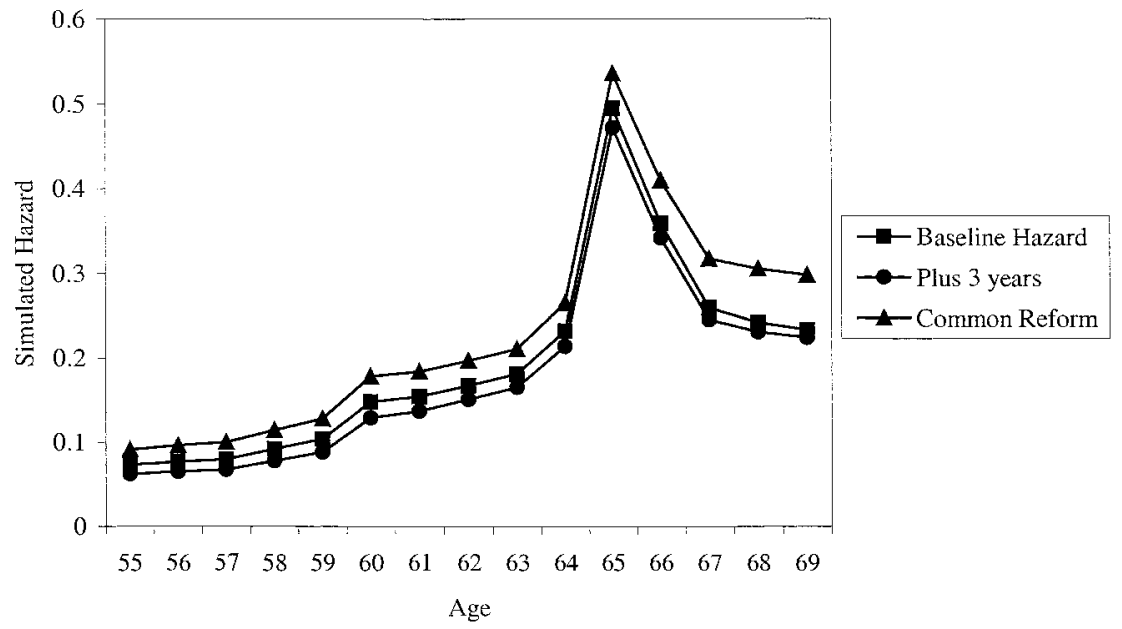

B

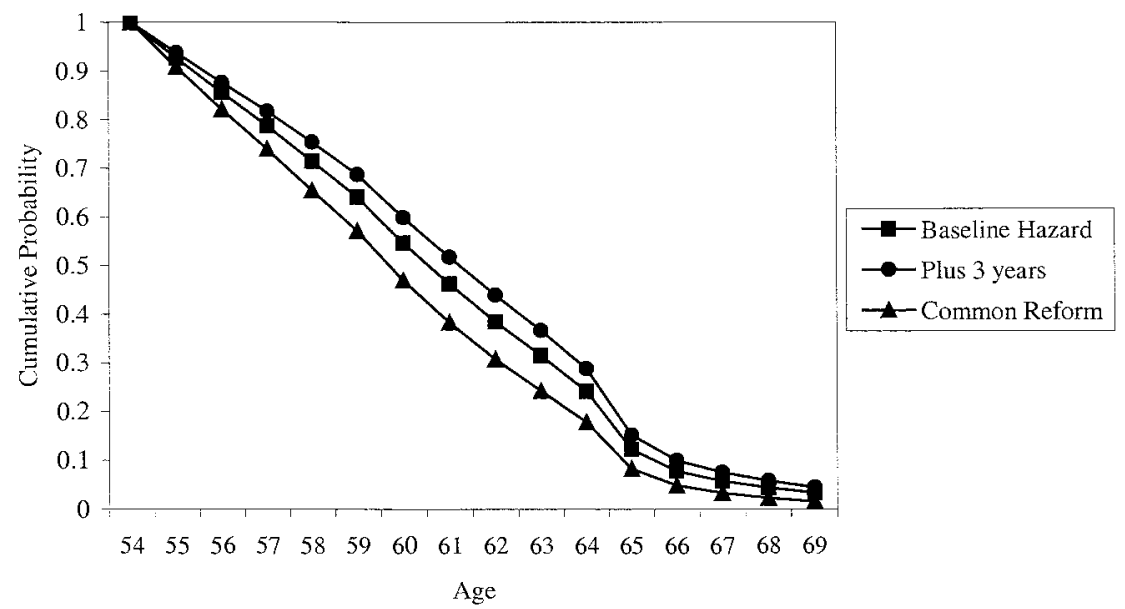

Fig. 2.13 S2 on males using option value estimates: $A$, Simulated hazard; $B$, Cumulative probability

In each of the models, the difference between the reform and baseline hazards is fairly uniform between ages fifty-five and fifty-nine. In this age range, only the higher level of ISW under the reform comes into play: Greater wealth leads to higher retirement rates. The effects are notably smaller using the option value model (figures 2.12, 2.13, and 2.14, panels A) reflecting the smaller coefficient on the level of ISW in the option value regression.

After age sixty, the distance between the reform hazard and the baseline hazard increases monotonically. The negative accruals resulting from the unfairness of the actuarial adjustment are exaggerated under the reform 
A

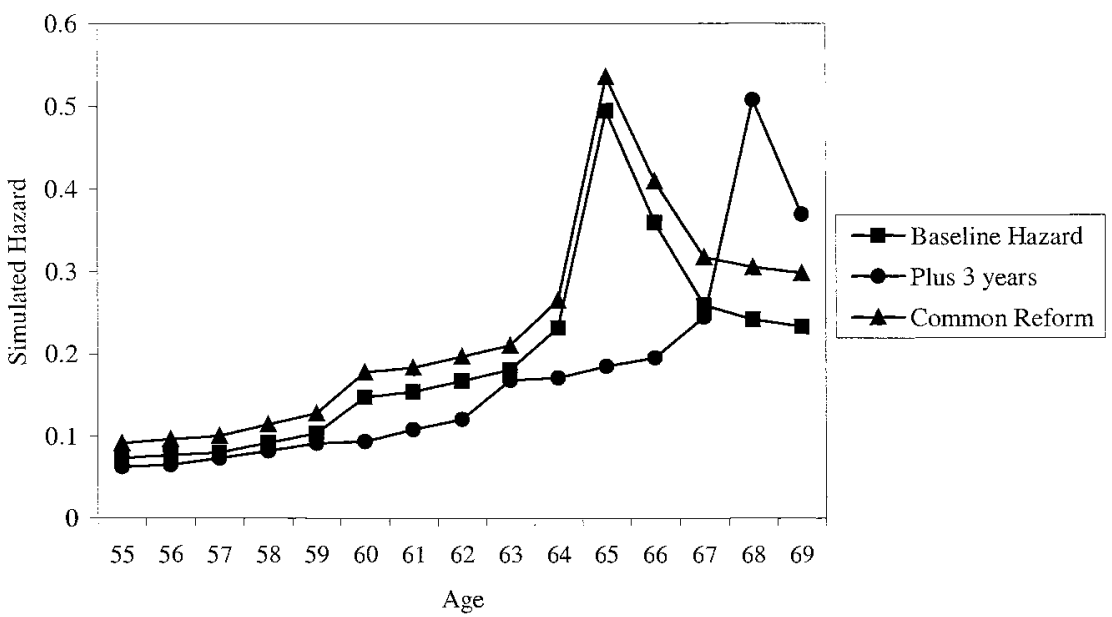

B

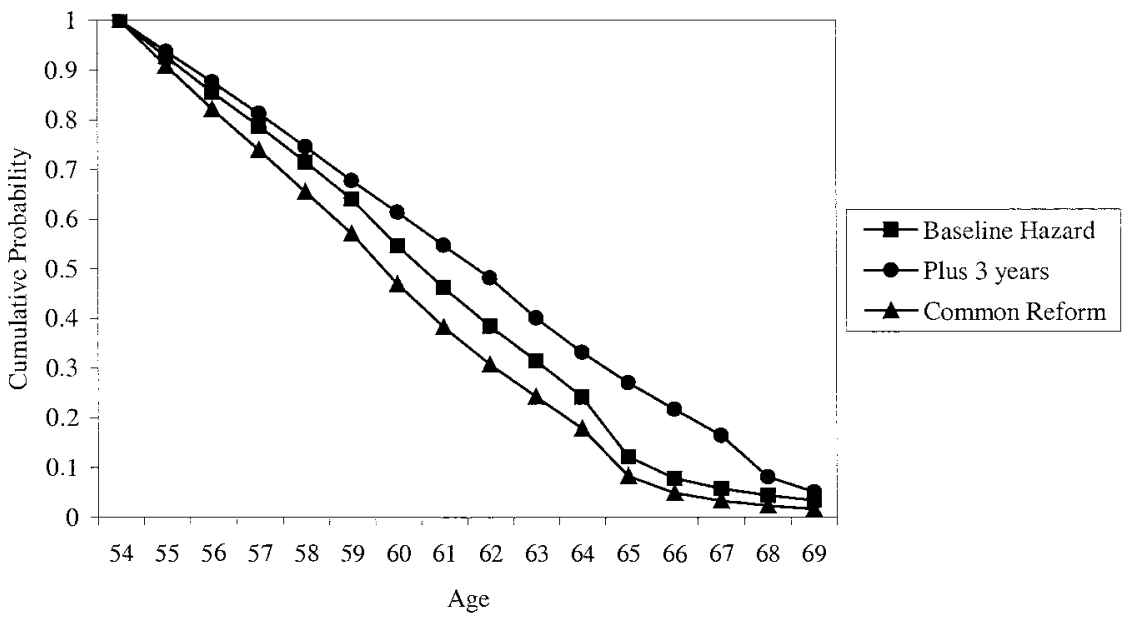

Fig. 2.14 S3 on males using option value estimates: $A$, Simulated hazard; $B$, Cumulative probability

due to the 60 percent replacement rate compared to the 25 percent replacement rate in the CPP/QPP. At higher ages, the unfairness of the adjustment increases, which explains the growth of the gap between the hazards. In the simulation using the accrual model (figures 2.6, 2.7, and 2.8, panels A), this growth in the gap between the (common) reform and baseline hazards is most stark. This is a result of the much larger estimated parameter on the accrual incentive measure compared to the estimated coefficients on the peak and option value measures.

Overall, the common reform simulations uncover two important messages. First, the wealth effects of moving to a more generous IS system 
A

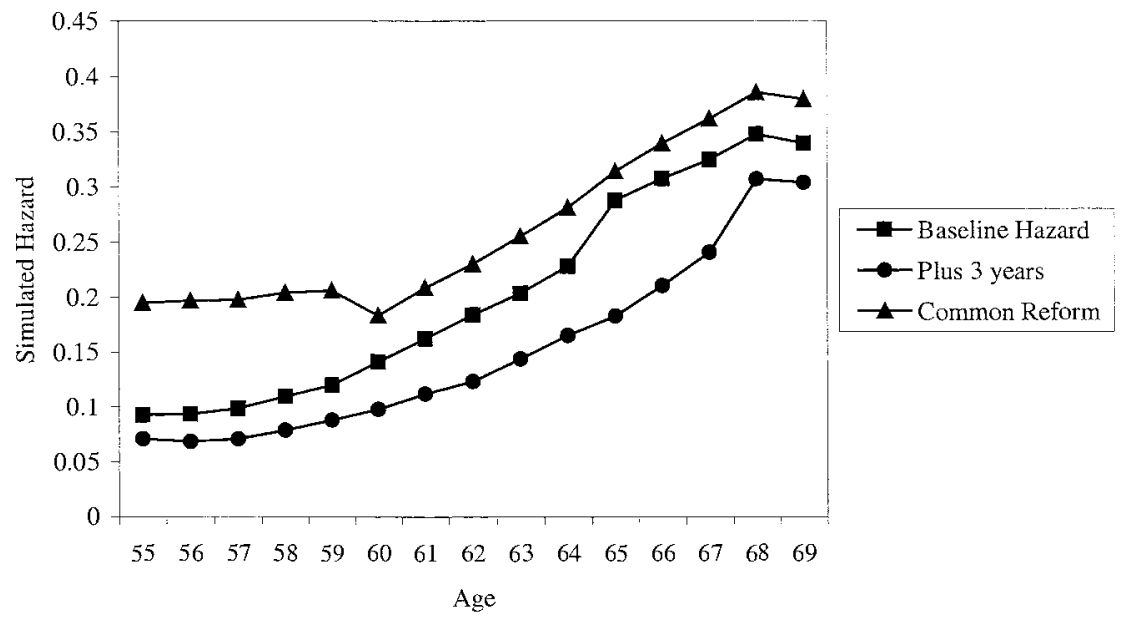

B

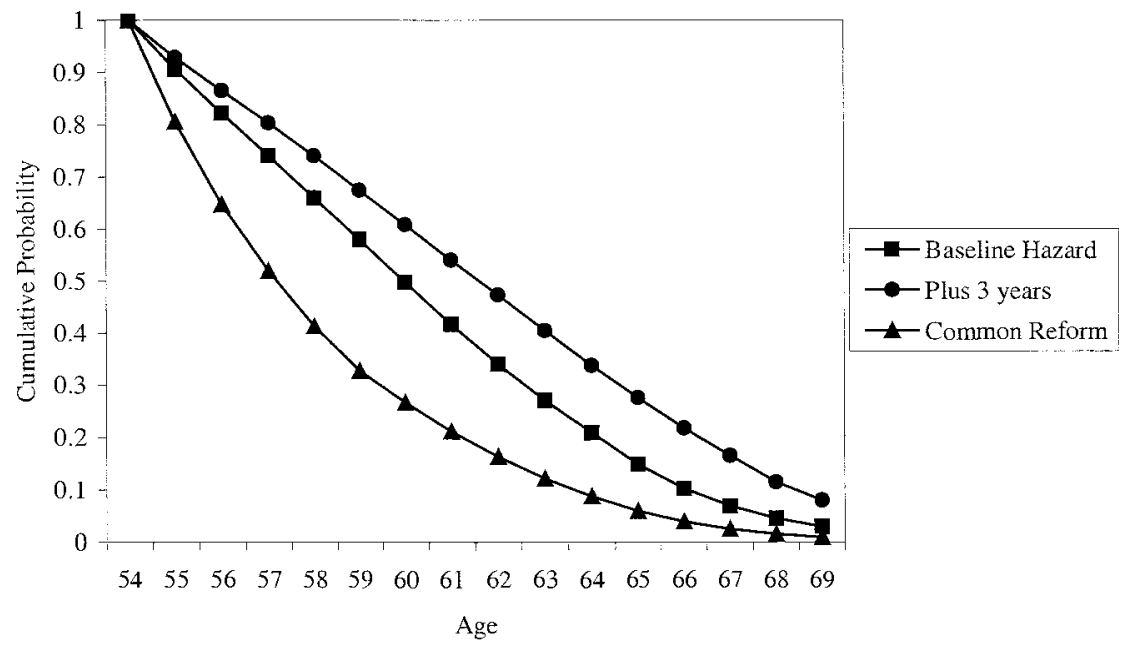

Fig. 2.15 S1 on females using accrual estimates: $A$, Simulated hazard; $B$, Cumulative probability

could have a large impact on retirement rates. Second, any unfairness in actuarial adjustments would have a much larger impact on retirement rates if all Canadian IS benefits were subject to the adjustments rather than just the CPP/QPP.

\subsection{Conclusions}

The aging of the Canadian population, coupled with a trend towards earlier retirement, places financial stress on the Canadian IS system. It is 
A

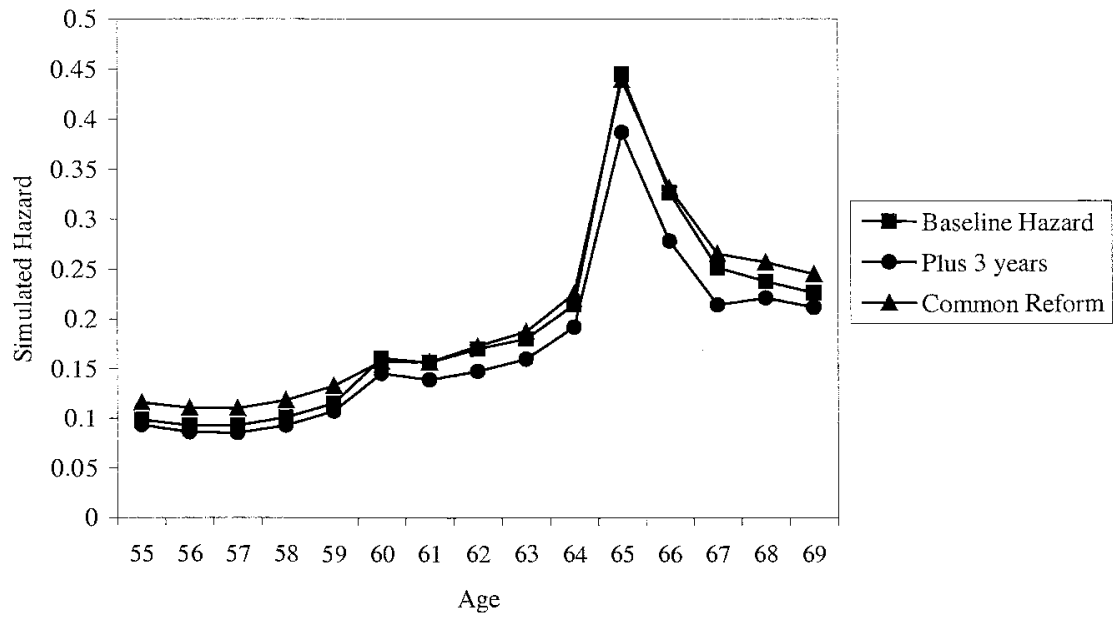

B

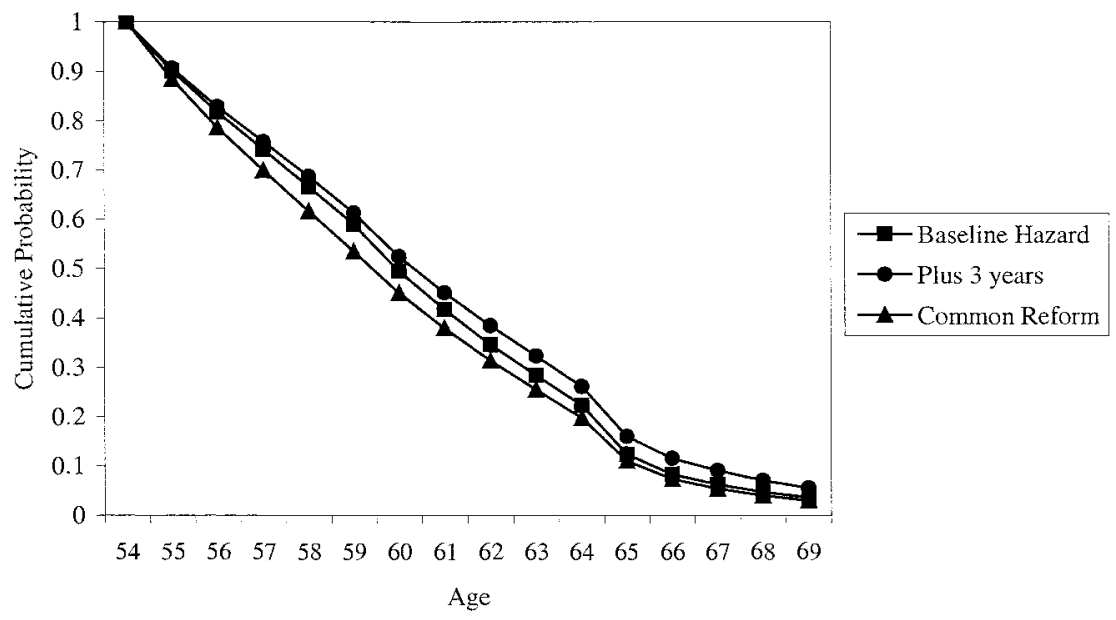

Fig. 2.16 S2 on females using accrual estimates: $A$, Simulated hazard; $B$, Cumulative probability

important, therefore, to understand how this complicated system affects retirement decisions. Other papers have suggested some role for IS programs, but no previous paper has taken a comprehensive look at how this panoply of programs affects retirement in Canada. This paper accomplishes this task, using an excellent data source matched to a rich simulation model that allows us to assign IS entitlements to our sample workers. Also, a variety of parameterizations of the incentives for retirement are considered.

We have two findings of importance. First, for the typical worker, the IS system provides increasingly strong disincentives to work after age sixty. 
A

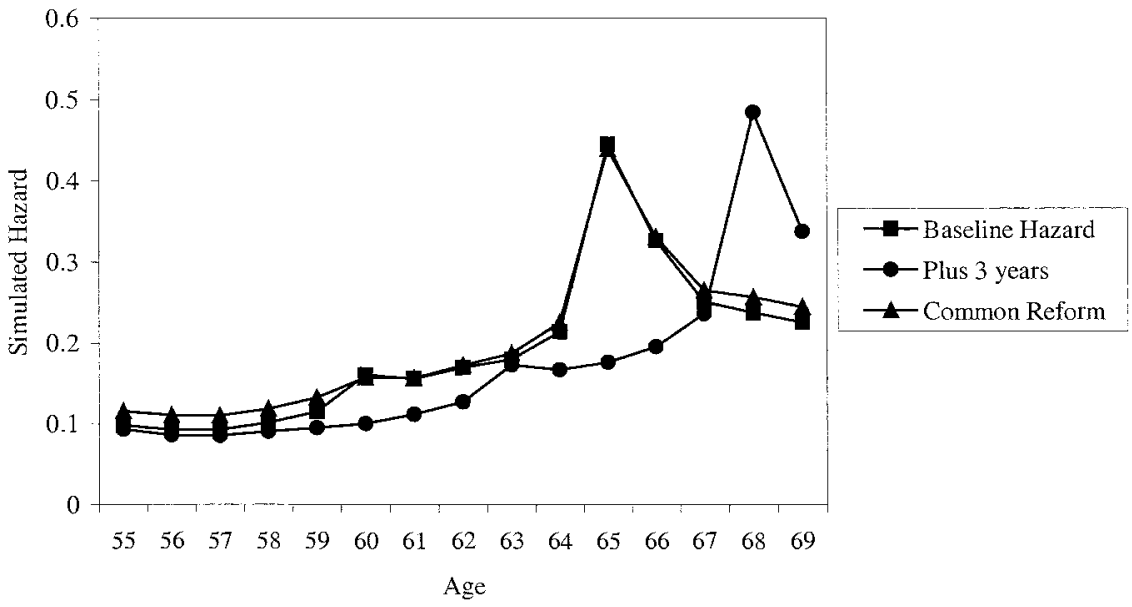

B

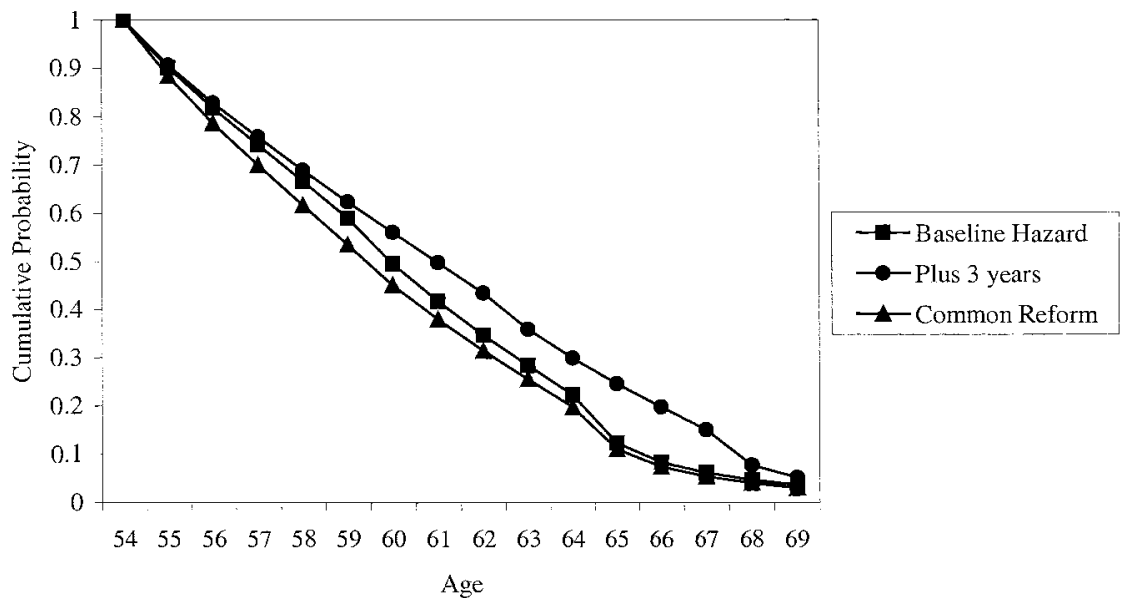

Fig. 2.17 S3 on females using accrual estimates: $A$, Simulated hazard; $B$, Cumulative probability

Workers actually see the present discounted value of there IS entitlement fall due to additional work after age sixty-one, and by age sixty-nine the reduction in IS entitlement amounts to 43 percent of what they would earn in that year. Second, there is a significant impact of these disincentives on work decisions. Using both one-year-forward measures and measures that account for the entire future path of incentives, we estimate that workers with larger returns to additional work are less likely to leave the labor force.

This finding in turn has implications for policy evaluation. Evaluations of changes to the Canadian IS system cannot be done assuming static retirement decisions; these evaluations must build in the type of dynamic retirement behavior that we observe. We illustrate these effects through two 
reforms and show that these changes can have important effects on the retirement decisions of older Canadian workers.

\section{Appendix}

\section{Data Descriptions and Sample Definitions}

\section{Longitudinal Worker File (LWF) Data: List of Variables from LWF data}

$A G E D D I F F$ : a variable recording the difference in age between an individual and their spouse (in years)

$A G E 55-A G E 69$ : a dummy variable that equals 1 if an individual is the indicated age and 0 otherwise ( $A G E 55$ is the excluded variable)

$A P E$ : a variable recording an estimate of an individual's current APE

Experience: a variable recording the number years since 1975 that an individual has had positive T-4 earnings

Married: a dummy variable that equals 1 if the individual is married and 0 otherwise

$R P P$ : a variable that ranges between 0 and 1 recording the proportion of workers in an individual's 3-digit industry that is a member of an RPP

Tenure: a variable recording the number of years since 1978 that an individual has been with the current firm

Tenure Censored: a dummy variable that equals 1 if an individual has been with their current firm continuously since 1978

Y85-Y95: a dummy variable that equals 1 in the indicated year and 0 otherwise ( $Y 90$ is the excluded variable)

S04-S500p: a dummy variable that equals 1 for the indicated size of the workforce at the place of work and 0 otherwise; categories are $0-4,5-19$, 20-49, 50-99, 100-199, 200-499, and 500+ (S5099 is the excluded variable)

INDI-IND10: a dummy variable that equals 1 for the indicated industry of employment and 0 otherwise (INDI is the excluded variable). The ten are

IND1: manufacturing (standard industrial classification [SIC] 100 to 399)

IND2: construction (SIC 400 to 449)

IND3: storage and transportation (SIC 450 to 499)

IND4: wholesale trade (SIC 500 to 599)

IND5: retail trade (SIC 600 to 699)

IND6: finance, insurance, and real estate (SIC 700 to 769)

IND7: business services (SIC 770 to 809 )

IND8: government services (SIC 810 to 849 )

IND9: education, health, and social services (SIC 850 to 909)

IND10: accommodation, food, and other services (SIC 910 to 999) 
$N F$ : a dummy variable that equals 1 if resident of Newfoundland and 0 otherwise

PEI: a dummy variable that equals 1 if resident of Prince Edward Island (PEI) and 0 otherwise

$N S$ : a dummy variable that equals 1 if resident of Nova Scotia and 0 otherwise

$N B$ : a dummy variable that equals 1 if resident of New Brunswick and 0 otherwise

$Q U$ : a dummy variable that equals 1 if resident of Quebec and 0 otherwise

$O N$ : a dummy variable that equals 1 if resident of Ontario and 0 otherwise (excluded variable)

$M B$ : a dummy variable that equals 1 if resident of Manitoba and 0 otherwise

$S A$ : a dummy variable that equals 1 if resident of Saskatchewan and 0 otherwise

$A B$ : a dummy variable that equals 1 if resident of Alberta and 0 otherwise $B C$ : a dummy variable that equals 1 if resident of British Columbia and 0 otherwise

TERR: a dummy variable that equals 1 if resident of Yukon or Northwest Territories and 0 otherwise

\section{Reconciliation of Sample Sizes from Longitudinal Worker File Data}

\section{Labour Market Activity Survey (LMAS) and}

Survey of Labour and Income Dynamics (SLID) Data

Cross-sectional samples from the 1986-1990 LMAS and the 1993-1995 SLID (see table 2A.1) address males or females, ages twenty-three to sixtynine who are paid workers in jobs in the month of September of the indicated year. The RPP coverage probabilities are calculated by three-digit industry code. Probabilities for 1991-1992 are simple linear interpolations of the 1990 and 1993 data.

\section{Census Family Files of the Canadian Census}

The data are from the 1986 and 1991 public-use micro-data files. In each year, males or females who are fifty-four and older are selected. Nonlabor income is defined as the sum of "investment income of census family or non-family person" plus "retirement pensions and other money income of census family or non-family person" plus "retirement pensions and other money income of census family or non-family person" (recorded separately as "Retirement Pensions, Superannuations and Annuities of census family or non-family person" and "Other Money Income of census family or non-family person" in the 1991 sample). Separating individuals who work (weeks and earnings greater than 0 ) and don't work (weeks and hours equal to 0 ), the probability that nonlabor income is positive, and its conditional mean are calculated for the following cells: 


\begin{tabular}{lrrrrr}
\hline & \multicolumn{2}{c}{ Observations } & & \multicolumn{2}{c}{ Individuals } \\
\cline { 2 - 3 } \cline { 6 - 6 } & \multicolumn{1}{c}{ Males } & Females & & Males & Females \\
\hline Base sample from LWF & 770,989 & 523,332 & & 141,182 & 103,726 \\
Missing earnings data & 20,306 & 10,165 & & 2,563 & 1,378 \\
Primary industries & 44,158 & 23,146 & & 6,444 & 4,387 \\
Already retired at age 55 & 99,196 & 100,203 & & 14,244 & 20,579 \\
Final sample & 607,329 & 389,808 & & 117,931 & 77,382 \\
\hline
\end{tabular}

Notes: The base sample is all individuals aged 55 to 69 in 1985, plus the cohorts of individuals who turn age 55 in years 1986 through 1991. The deletions for missing earnings data are due to nonsensical earnings records for some individuals in Quebec in 1992 (e.g., some individuals with earnings of $\$ 46$ billion). An attempt was made to replace these records with information from an alternative T-4 data set for this year. This was not successful in all cases, however, which led to the deletion of all observations for these individuals. The deletions for employment in primary industries are explained in the text. The sample is conditioned on employment at age 55, so individuals with 0 earnings at this age are deemed to have already retired and are thus deleted from the data set.

Males who are employed: by region (East, Ontario, or West), by industry (manufacturing; construction; transportation and communications; wholesale and retail trade; financial, insurance, and real estate [FIRE] and business services; government, health, and education services; or accommodation, food, beverage, and other services), and by age ( $54-55$, $56-57, \ldots, 60-61,62-64,65+)$;

Males who are not employed: by region (East, Ontario, or West), by marital status (married; spouse's age $<1$; married, spouse's age $=$ age $+1 /-1$; married, spouse's age $>$ age +1 ; not married), and by age (54-60, 61$63,64-66, \ldots, 73-75,76+)$;

Females who are employed: by region (East, Ontario, or West), by industry (manufacturing; construction; transportation and communications; wholesale and retail trade; FIRE and business services; government, health, and education services; or accommodation, food, beverage, and other services), and by age (54-55, 56-57, . ., 60-61, 62-64, 65+);

Females who are not employed: by region (East, Ontario, or West), by marital status (married, spouse's age $<$ age -1 ; married, spouse's age $=$ age $+1 /-1$; married, spouse's age $>$ age +1 ; not married), and age (54-60, $61-63,64-66, \ldots, 73-75,76-80,81+)$.

\section{References}

Baker, Michael. 2002. The retirement behavior of married couples: Evidence from the spouse's allowance. Journal of Human Resources 37 (Winter): 1-34.

Baker, Michael, and Dwayne Benjamin. 1999a. Early retirement provisions and the 
labour force behavior of older men: Some evidence from Canada. Journal of Labour Economics 17 (October): 724-56.

1999b. How do retirement tests affect the labour supply of older men? Journal of Public Economics 71 (January): 27-51.

2000. Public pension programs and attachment to the labour force. In Adapting public policy to a labour market in transition, ed. F. St-Hilaire and W. C. Riddell, 287-315. Montreal: Institute for Research on Public Policy (IRPP).

2001. Working time over the life-cycle: Do public pensions matter? In

Working time in comparative perspective. Vol. 2, Life-cycle working time and nonstandard work, ed. Susan Houseman and Alice Nakamura, 181-216. Kalamazoo, Mich.: W. E. Upjohn Institute.

Baker, Michael, Jonathan Gruber, and Kevin Milligan. 2003. The retirement incentive effects of Canada's income security programs. Canadian Journal of Economics 36 (2): 261-90.

Burbidge, John. 1987. Social security in Canada. Canadian Tax Paper no. 79. Toronto: Canadian Tax Foundation.

Coile, Courtney. 1999. Retirement incentives and couples' retirement decisions. Ph.D. diss. MIT, Department of Economics, Cambridge, Massachusetts.

Coile, Courtney, and Jonathan Gruber. 2000. Social security and retirement. NBER Working Paper no. 7830. Cambridge, Mass.: National Bureau of Economic Research, August.

Compton, Janice. 2001. Determinants of retirement: Does money really matter? Department of Finance Working Paper no. 2001-02. Department of Finance, Government of Canada.

Gruber, Jonathan. 1999. Social security and retirement in Canada. In Social security and retirement around the world, ed. Jonathan Gruber and David Wise, 73100. Chicago: University of Chicago Press.

Gruber, Jonathan, and Brigitte Madrian. 1995. Health insurance availability and the retirement decision. American Economic Review 85 (4): 938-48.

Pesando, James E., and Samuel A. Rea. 1977. Public and private pensions in Canada: An economic analysis. Toronto: University of Toronto Press.

Picot, Garnett, and Zhengxi Lin. 1997. Are Canadians more likely to lose their jobs in the 1990s? Analytical Studies Branch Research Paper no. 96. Ottawa: Statistics Canada.

Statistics Canada. 1983. Historical statistics of Canada. 2nd ed. Catalogue no. E86103. Ottawa: Statistics Canada.

- 1984. Life tables, Canada and provinces 1980-1982. Catalogue no. 84-532. Ottawa: Statistics Canada.

- 1998a. Survey of consumer finances, individual files (1997 income year). Ottawa: Statistics Canada.

. 1998b. Permanent layoffs, quits and hirings in the Canadian economy. Catalogue no. 71-539-XIB. Ottawa: Statistics Canada.

-1999. Pension plans in Canada. Catalogue no. 74-401-XPB. Ottawa: Statistics Canada.

Various years. Canadian census. Ottawa: Statistics Canada.

Stock, James H., and David A. Wise. 1990. Pensions, the option value of work, and retirement. Econometrica 58 (5): 1151-80.

Tompa, Emile. 1999. Transitions to retirement: Determinants of age of social security take up. Social and Economic Dimensions of an Aging Population (SEDAP) Working Paper no. 6. Ontario: SEDAP. 